Check for updates

Cite this: Mater. Adv., 2022, 3, 2309

Received 12th November 2021 Accepted 17th January 2022

DOI: $10.1039 / \mathrm{d} 1 \mathrm{ma01062j}$

rsc.li/materials-advances

\section{Engineering Schottky-like and heterojunction materials for enhanced photocatalysis performance - a review}

\author{
Priyanka Kumari, ${ }^{\mathrm{ab}}$ Nupur Bahadur, ${ }^{\mathrm{c}}$ Lingxue Kong, (D) ${ }^{\mathrm{a}}$ Luke A. O’Dell, (D) a \\ Andrea Merenda (iD d and Ludovic F. Dumée (D) *efg
}

\begin{abstract}
Photocatalysis with nanostructured semiconductors is one of the most widely used technologies for environmental remediation. However, the issues related to conventional photocatalysis such as fast recombination of photo-generated electron and hole pairs and poor redox abilities of the charge carriers need to be addressed to improve the properties and catalytic performance of semiconductor based photocatalysts. The engineering of metal/semiconductor interfaces to develop Schottky-like materials and semiconductor/semiconductor interfaces to design heterojunction materials offers spatial charge separation, leading to suppressed recombination of charge carriers and enhanced catalytic performance. Therefore, Schottky-like and heterojunction materials have emerged as a promising solution to the limitations associated with conventional photocatalysis. This review compares the fundamentals, various structures, configurations and charge transfer pathways of Schottky-like and heterojunction materials together. The physicochemical properties of recently developed Schottky-like and heterojunction materials were further correlated with the photocatalytic degradation of common dyes and persistent organic pollutants in wastewater. This review exemplifies the commonly used metals such as $\mathrm{Ag}, \mathrm{Au}, \mathrm{Pt}, \mathrm{Zn}$, and $\mathrm{Bi}$ and semiconducting materials such as $\mathrm{TiO}_{2}, \mathrm{ZnO}, \mathrm{CdS}, \mathrm{g}-\mathrm{C}_{3} \mathrm{~N}_{4}, \mathrm{MnO}_{2}$, $\mathrm{Fe}_{2} \mathrm{O}_{3}$, and $\mathrm{BiVO}_{4}$ for the preparation of Schottky-like and heterojunction materials. Furthermore, the challenges and the perspective towards the enhancement of materials design and properties of Schottky-like and heterojunction structures are also provided.
\end{abstract}

\section{Introduction}

Challenges associated with environmental pollution from chemicals may be remediated by using advanced oxidative processes and catalysis through selective and fast degradation of persistent organic pollutants (POPs). ${ }^{1}$ Efficient photo-catalyses however require (i) slow recombination of photo-generated

${ }^{a}$ Deakin University, Geelong, Institute for Frontier Materials, Waurn Ponds, 3216, Victoria, Australia. E-mail: pkumari@deakin.edu.au

${ }^{b}$ TERI-Deakin Nano-Biotechnology Centre (TDNBC), Teri Gram, Gwal Pahari, Gurugram 122003, Haryana, India

${ }^{c}$ TADOX ${ }^{\mathbb{R}}$ Technology Centre for Water Reuse, Water Resources Division, The Energy and Resources Institute (TERI), India Habitat Centre, Lodhi Road, New Delhi-110003, India. E-mail: nupur.bahadur@teri.res.in

${ }^{d}$ School of Science, RMIT University, 124 La Trobe Street, Melbourne, Victoria, Australia

${ }^{e}$ Khalifa University, Department of Chemical Engineering, Abu Dhabi, United Arab Emirates

${ }^{f}$ Research and Innovation Center on $\mathrm{CO}_{2}$ and Hydrogen, Khalifa University, Abu Dhabi, United Arab Emirates

${ }^{g}$ Center for Membrane and Advanced Water Technology, Khalifa University, Abu Dhabi, United Arab Emirates. E-mail: ludovic.dumee@ku.ac.ae electron and hole pairs and (ii) strong redox potential to support high electron transfer across the materials. ${ }^{2}$ The emergence of advanced nanostructured and nano-layered photocatalysts has opened the path to multidisciplinary research towards the tailoring of physicochemical, structural and optoelectronic properties to promote enhanced catalysis of organic pollutants.

The options for the enhancement of catalytic performance and visible light activation of the materials involve metal or non-metal doping of semiconductors ${ }^{3}$ and defect engineering in catalytic nanostructures such as graphene. ${ }^{4}$ The most promising engineering strategy involves the design of electronic barriers, which are introduced at the junction of a conductive and a semiconducting layer. ${ }^{5}$ The interface between the conductive layer, typically a metal or carbon surface, and the semiconducting material, often a metal oxide, may lead to the development of two types of junctions, either Ohmic or Schottky-like junctions. ${ }^{6}$ On the one hand, an Ohmic junction is formed when the semiconducting materials offer a higher work function than the conducting one. ${ }^{7}$ An Ohmic contact however offers a sustained flow of electrons between the metal 
and the semiconducting material in both forward and reverse biased directions, thereby hindering the separation of charge carriers and leading to poor photo-response capabilities. ${ }^{8}$ On the other hand, Schottky-like junctions are formed when semiconducting materials exhibit a lower work function than the conductive material, leading to a unilateral flow of electrons only in the forward biased direction, thus enabling efficient charge separation. ${ }^{6}$ Schottky-like materials have been particularly applied in photo-electronics, solar cells, $\mathrm{H}_{2}$ production and power rectifiers, and circuit applications, offering high current density, low forward voltage drop, and low power consumption, leading to high efficacy devices. The design of Schottky-like photocatalysts therefore supports efficient charge separation and enhanced transport of electrons and holes through the materials, subduing their recombination and foremost enhancing the catalysis. ${ }^{9}$

Another class of advanced photo-catalytic materials is referred to as heterojunctions, which are generated upon engineering of the intimate interfaces between at least two semiconducting materials offering different band-gaps. ${ }^{10,11}$ The major benefit of heterojunction fabrication over conventional doping is the efficient production of a larger density of charge carriers from the multiple semiconducting interfaces. ${ }^{11}$ Therefore, designing heterojunction structures may represent a scalable and cost-effective strategy to mitigate challenges associated with conventional photo-catalysts, since the interface between the two semiconducting materials may overcome the drawbacks associated with individual components. ${ }^{12}$ The nature of these multi-layered structures also offers opportunities to develop alternative catalytic processes, by combining photo, electro and thermal activation to further enhance the reactivity, kinetics and potentially selectivity of the catalysts. ${ }^{13}$ Multiple reviews are available, which elaborate the recent advances on Schottky junction solar cells. ${ }^{14-16}$ Reviews targeting the catalytic remediation of wastewater using Schottky-like materials are limited. Recently, a review covered the fundamentals, structures and photocatalytic applications of Schottky-like materials ${ }^{17}$ and to date, only one review has presented the correlation and paradox in the mechanism of Schottky barriers and surface plasmon effects for enhancing the photocatalytic reactions. ${ }^{18}$ Another review focused on the basic principles of heterojunction photocatalysts and their application towards various photocatalytic reactions. ${ }^{19}$ The most recently published review article on heterojunction based photocatalysts discussed the synthetic pathways, and different configurations of heterojunctions, and further correlated with photocatalytic applications such as $\mathrm{H}_{2}$ production, $\mathrm{CO}_{2}$ reduction and organic dye degradation. ${ }^{12}$

This review critically presents and compares Schottky-like and heterojunction materials to develop next generation photocatalytic materials with an enhanced response rate and electron generation/transfer selectivity. The design and development of material configurations involving conducting/semiconducting layers in Schottky-like interfaces or as heterojunction-based structures is reviewed from a materials engineering and operation point of view. The physico-chemical properties and catalytic mechanisms of recently developed Schottky-like and heterojunction-based photocatalytic materials are discussed towards the degradation of common dyes and persistent organic pollutants to offer new perspectives on the integration of such materials into effective heterogeneous catalytic systems for wastewater degradation.

\section{Structures and charge separation mechanisms of Schottky-like materials}

The formation of Schottky-like barriers occurs at the junction of the metal and the n-type semiconducting materials when the work function $\left(\phi_{\mathrm{M}}\right)$ of the metal is higher. The majority of charge carriers in p-type semiconductors are positive holes, which would attract electrons from the metal side, leading to the neutralization of the semiconducting material. ${ }^{20}$ Therefore, n-type semiconducting materials are generally used in the formation of Schottky-like barriers. The work function of a metal represents the energy required to accelerate an electron from the Fermi level of the metal to vacuum (Fig. 1(A)). ${ }^{18}$ Since metals are, by nature, more conductive than oxides, they exhibit a lower Fermi energy $\left(E_{\mathrm{Fermi}}\right)$ than semiconducting materials. ${ }^{18}$ The Fermi level of semiconducting materials lies just below
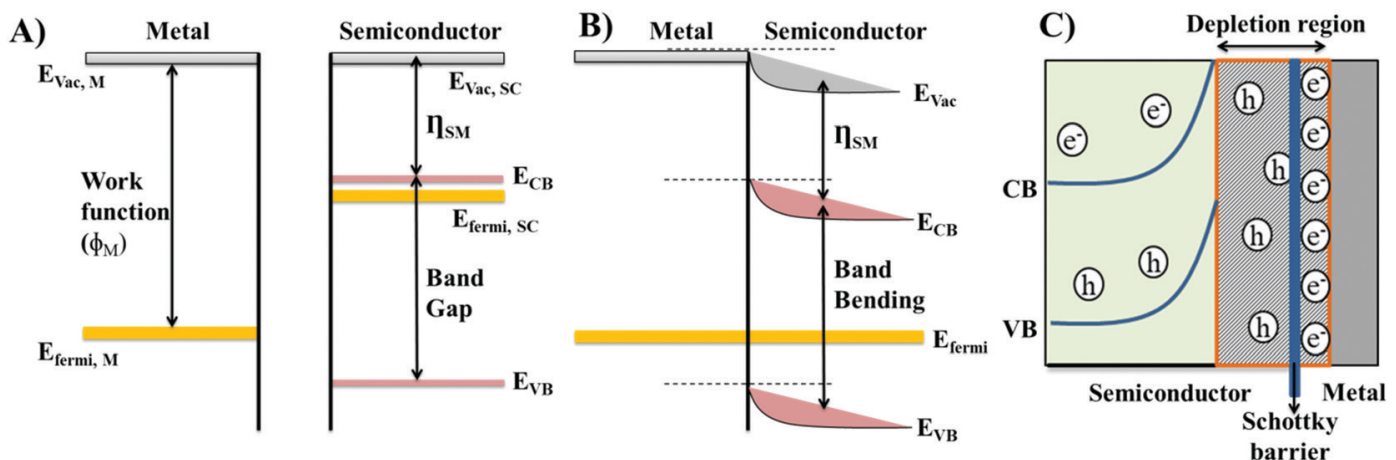

Fig. 1 (A) Band structures of the metal and the $n$-type semiconducting material before contact. (B) Band structures of the metal and the $n$-type semiconducting material after contact. (C) Schematic representation of the flow of charge carriers and creation of a depletion region and Schottky-like barrier at the junction of the metal and the $n$-type semiconducting material. 
their conduction band and the difference between the energies of the lowest occupied conduction band (CB) and vacuum energy is called, for semiconducting materials, the electro affinity $\left(\eta_{\mathrm{SM}}\right) .^{21}$ As the semiconducting material and metal comes in contact during Schottky-like barrier generation, the electrons will flow from the higher $E_{\mathrm{Fermi}}$ of the semiconducting material to the lower $E_{\mathrm{Fermi}}$ of the metal, until an equilibrium stage is reached with a constant $E_{\mathrm{Fermi}}$ across both materials, called the band bending ${ }^{22}$ (Fig. 1(B)). The flow of electrons from the semiconducting material to the metal leads to a depletion of electrons within the semiconducting material, supporting the accumulation of positive holes within the semiconducting material but near the semiconductor/metal interface. ${ }^{2-24}$ Meanwhile, the electrons accumulate within the metal but near the very same interface to maintain electrical neutrality (Fig. 1(C)). This mechanism leads to the formation of a depletion layer at the junction, which generates a localised potential barrier for the charge carriers, referred to as the Schottky-like barrier (Fig. 1(C)). The charge carriers must overcome the Schottky-like barrier to continue migration across the metal/ semiconductor interface. ${ }^{18}$ Schottky-like barriers work effectively for electron trapping, restricting the electron flow back to the semiconducting bulk material, which in turn reduces the recombination of photo-generated electron and hole pairs. ${ }^{25}$ Therefore, the Schottky like properties occurring at the metal/ semiconductor interface further enhance the generation of reactive oxygen species (ROS), leading to an enhancement in the catalytic performance of the materials. ${ }^{26,27}$

Surface plasmon resonance (SPR) is basically the oscillation of electrons at the junction between a semiconductor and metal. ${ }^{28}$ On the irradiation of light (electric field), the electron density on the metal gets redistributed leading to a decrease of electron density at one side of the metal, while on the other side of the metal the electron density increases. ${ }^{29}$ This creates an inbuilt electric field inside and outside the metal, which is in the opposite direction of the applied electric field, causing a series of charge density oscillations. ${ }^{30}$ The phenomenon of creation of an in-built electric field and oscillation of electrons are called as surface plasmon resonance (SPR) or localised surface plasmon resonance (LSPR). ${ }^{30}$ Upon irradiation with visible light, noble metal nanoparticles such as $\mathrm{Ag}, \mathrm{Au}$, and $\mathrm{Pd}$ also produce hot electrons due to the surface plasmon effect (SPR). ${ }^{31}$ These hot electrons possessing higher energies are able to cross the Schottky barrier and drift towards the $\mathrm{CB}$ of the adjacent semiconducting material, while the holes in the semiconducting materials start drifting towards the metal due to the intrinsic electromagnetic field. ${ }^{32}$ Therefore, the SPR effect is responsible for reversing the charge transfer mechanism at the metal/semiconductor interface. ${ }^{33}$ Under the SPR effect, the hotelectrons at the $\mathrm{CB}$ of semiconducting materials assist the photo-reduction of $\mathrm{O}_{2}$ to produce superoxide ions $\left({ }^{\bullet} \mathrm{O}_{2}{ }^{-}\right) \cdot{ }^{34,35}$ The holes accumulated on the surface of metal nanoparticles assist the photo-oxidation of $\mathrm{H}_{2} \mathrm{O}$ molecules to generate hydroxyl radicals $\left(\mathrm{OH}^{\bullet}\right) .^{34}$

The fundamental influence of the Schottky barrier on the photocatalytic mechanism has been very well recognized. ${ }^{18}$ However, the SPR mechanism in photocatalytic enhancement still remains incoherent because the whereabouts of the excited hot electrons from metal to the photocatalyst are still underdeveloped and opposite to the basic law of Schottky barrier in which the electrons are supposed to migrate towards the metal surface from the photocatalysts (Fig. 2). ${ }^{36}$

The structures of Schottky-like materials fall into four main categories - conventional, core-shell, 2D nano-sheet, and multi-junction structures ${ }^{8}$ (Fig. 3). The conventional Schottkylike structures are formed when the grouping of metal and semiconducting materials is not precisely controlled, leading to scattered deposition of metal nanoparticles across the surface of the semiconducting materials, as shown in the schematic representation in Fig. 3(A) ${ }^{8,37}$ Conventional Schottky-like structures such as $\mathrm{Pt} / \mathrm{TiO}_{2}$ were fabricated by immersing and photoradiating $\mathrm{TiO}_{2}$ nano-sheets under $\mathrm{UV}$ light in a $\mathrm{H}_{2} \mathrm{PtCl}_{6}$ solution, leading to the reduction of the platinum ions in solution to $\mathrm{Pt}$ metal on the surface of $\mathrm{TiO}_{2}$ nano-sheets. ${ }^{38}$ $\mathrm{H}_{2} \mathrm{PtCl}_{6}$ was also added to a $\mathrm{TiO}_{2}$ nanotube suspension, followed by stirring and solvent evaporation, leading to the formation of powdered nano-composite materials with $2 \mathrm{~nm}$ sized metal nanoparticles randomly scattered at the surface of a semiconducting core. Calcination of the powdered nanocomposite in a reducing atmosphere led to the design of conventional $\mathrm{Pt} / \mathrm{TiO}_{2}$ nanotubes with Schottky-like properties. ${ }^{39}$ Chemical vapour deposition was also used to synthesize conventional Schottky-like structures by vaporizing $\mathrm{HAuCl}_{4}$ at high temperature and subsequently blowing the vapours onto the surface of $\mathrm{TiO}_{2}$ nanorods at a lower temperature under an inert gas atmosphere, leading to the fabrication of $\mathrm{Au} / \mathrm{TiO}_{2}$ nanorods. ${ }^{40}$ Metal Au nanoparticles of size $20 \mathrm{~nm}$ were deposited uniformly on the surface of $\mathrm{TiO}_{2}$ nanorods, shown in the TEM image of $\mathrm{Au} / \mathrm{TiO}_{2}$ exhibiting a conventional Schottky-like structure in Fig. 3(A). ${ }^{40}$ The morphology and specific surface area (SSA) of the semiconducting materials in the conventional Schottky-like structure did not change significantly due to

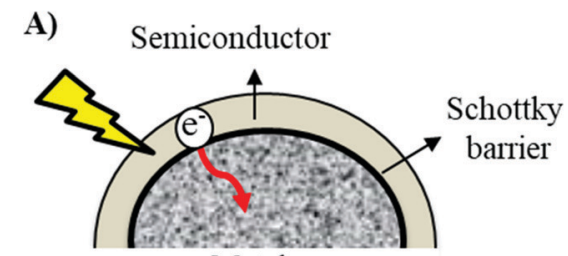

Metal

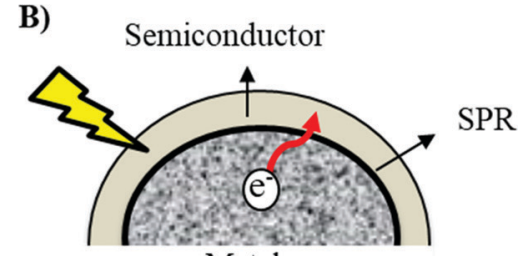

Metal

Fig. 2 The proposed electron pathway during (A) Schottky barrier formation and (B) surface plasmon resonance (SPR). 

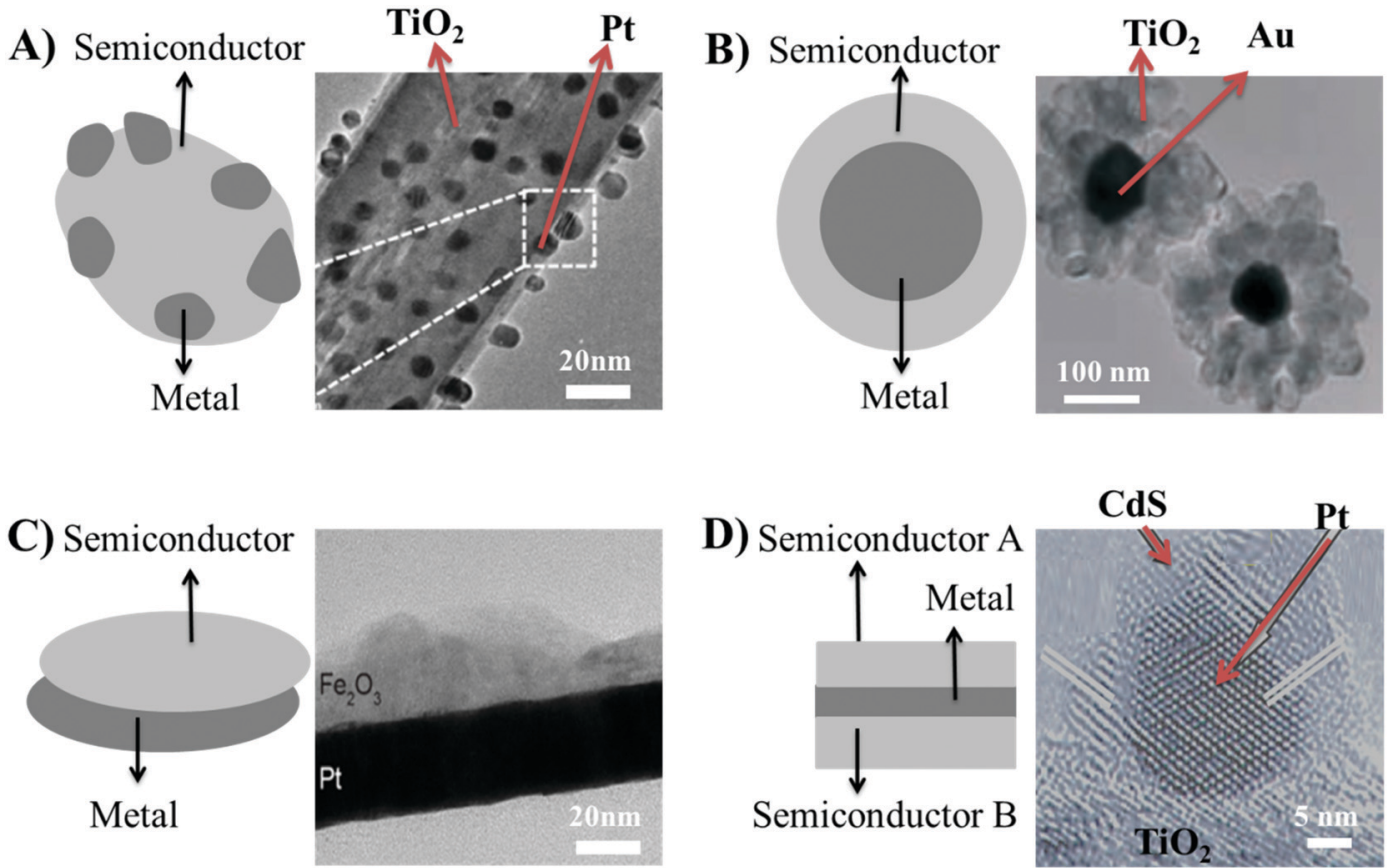

Fig. 3 (A) Schematic representation of the conventional Schottky-like structure and TEM image of the $\mathrm{Au} / \mathrm{TiO}_{2}$ junction exhibiting the conventional Schottky-like structure, reprinted with permission from Wiley; ${ }^{40}$ (B) schematic representation of the core-shell structure and TEM image of flower like $\mathrm{Au} / \mathrm{TiO}_{2}$ nanostructures exhibiting the core-shell Schottky-like structure, reprinted with permission from Wiley; ${ }^{44}$ (C) schematic representation of the $2 \mathrm{D}$ nanosheet Schottky-like structure and TEM image of $\mathrm{Pt} / \mathrm{Fe}_{2} \mathrm{O}_{3}$ exhibiting the formation of nanosheet Schottky-like structure reprinted with permission from Elsevier; ${ }^{50}$ (D) schematic representation of multi-junction Schottky-like structure and TEM image of the $\mathrm{CdS} / \mathrm{Au} / \mathrm{TiO} \mathrm{O}_{2}$ multi-junction Schottky-like structure, reprinted with permission from Springer. ${ }^{53}$

nano-sized deposition of metal particles $(2-20 \mathrm{~nm})$. The intrinsic properties of spherical metal nanoparticles do not allow intimate contact with the semiconducting materials, which leads to insufficient separation of charge carriers. Therefore, new structures of Schottky-like materials need to be explored.

Core-shell structures are formed by encapsulating metal nanoparticles within semiconducting materials, resulting in a strong contact between the metal and the semiconducting material at the interface, ${ }^{41}$ as shown in the schematic in Fig. 3(B). The core-shell structures also enable efficient charge separation, thus preventing agglomeration and providing protection to the metal surface against coalescence and corrosion during heat treatment processes or, if exothermic, photocatalytic reactions. ${ }^{42,43}$ The synthesis of core-shell Schottky-like structures such as $\mathrm{Au} / \mathrm{TiO}_{2}$ involved processes such as the hydrothermal preparation of core Au metal nanoparticles from the mixture of $\mathrm{HAuCl}_{4}$ and $\mathrm{Na}_{3} \mathrm{C}_{6} \mathrm{H}_{5} \mathrm{O}_{3}$ in sodium citrate solution under vigorous stirring. The solution containing core $\mathrm{Au}$ metal nanoparticles was transferred to an autoclave, followed by the addition of $\mathrm{TiF}_{4}$ solution and continuous heating for $48 \mathrm{~h}$, which led to the aggregation of $\mathrm{TiO}_{2}$ crystallites on the surface of $\mathrm{Au}$ nanoparticles. The process led to the synthesis of core $\mathrm{Au}$ metal nanoparticles of size $50-150 \mathrm{~nm}$, followed by aggregation of $\mathrm{TiO}_{2}$ crystallites in a shell-like pattern on the surface of $\mathrm{Au}$ nanoparticles as shown in the TEM image in Fig. 3(B) ${ }^{44}$ The core shell structures allowed the manipulation of the crystallite size of the metal core depending on the application, simply by injecting the metal precursor sol into the voids. ${ }^{44,45}$ The core shell Schottky-like structures also induced selectivity towards target pollutants as only the chemical species permeable through the outer inorganic shells could access the interior metal core and undergo metal catalysed reactions. ${ }^{46}$ The core shell structures offer several advantages over conventional Schottky structures; therefore, it is one of the sought after synthetic approaches to achieve higher selectivity and catalysis of pollutants. ${ }^{44,47}$

Two-dimensional (2D) nano-sheets of semiconducting metal oxides can offer superior photo-electrochemical properties due to their chemically active facets and edges, as well as a higher specific surface area (SSA), compared to bulk particles, thereby providing a higher density of photo-electro active sites. ${ }^{48} \mathrm{TiO}_{2}$ nano-sheets exhibited a SSA of up to $250 \mathrm{~m}^{2} \mathrm{~g}^{-1}$, while commercial P-25 anatase $\mathrm{TiO}_{2}$ nanoparticles only exhibited a SSA of up to $50 \mathrm{~m}^{2} \mathrm{~g}^{-1}$. ${ }^{49}$ The deposition of metal oxide 2D nano-sheets onto metal substrates to develop Schottky-like structures is therefore highly sought after (Fig. 3(C)). The fabrication of $2 \mathrm{D} \mathrm{Fe}_{2} \mathrm{O}_{3}$ nano-sheets on Pt metal substrates was achieved using area-selective atomic layer deposition, which led to the formation of clearly defined interfaces between the $\mathrm{Fe}_{2} \mathrm{O}_{3}$ layer and the underneath Pt substrate, as shown across the TEM image in Fig. $3(\mathrm{C}) \cdot{ }^{50}$ Such an arrangement provides Schottky-like characteristics to the material. Atomic layer deposition offered precise control over the thickness of the metal oxides at the atomic level alowing for the synthesis of metal oxide coatings with a 2D structured morphologies, which provided Schottky-like characteristics to the materials. ${ }^{51}$ 
Multi-junction Schottky-like structures can also be formed by sandwiching metal nanoparticles between two semiconducting materials, as schematically represented in Fig. 3(D). ${ }^{52}$ The multi-junction Schottky-like structures endow more efficient charge separation than any other structures as the sandwiched metal nanoparticles act as an electron mediator. This configuration supports fast carry-over of electrons from the conduction band (CB) of one semiconductor $\mathrm{A}$, with a higher oxidation potential, to the valence band (VB) of the semiconductor $\mathrm{B}$, with a higher reduction potential. ${ }^{52}$ Therefore, spatial separation of charge carriers leads to the occurrence of oxidation reactions on semiconductor A, while semiconductor B only allows reduction reactions to happen. ${ }^{52}$ An example of a multijunction $\mathrm{CdS} / \mathrm{Au} / \mathrm{TiO}_{2}$ was fabricated by a two-step reaction, whereby the first step involved the addition of $\mathrm{TiO}_{2}$ particles in $\mathrm{HAuCl}_{4}$ and $\mathrm{NaOH}$ solution, followed by stirring and solvent evaporation. The second step involved the UV-assisted reaction between sulphur and cadmium perchlorate to support the deposition of CdS onto the surface of $\mathrm{Au} / \mathrm{TiO}_{2}$, thus providing multi-junction Schottky-like characteristics to the composite material. ${ }^{53}$ The structure between $\mathrm{CdS} / \mathrm{Au} / \mathrm{TiO}_{2}$ is shown in the TEM image in Fig. 3(D), illustrating $\mathrm{TiO}_{2}$ nanosheets anchored with $\mathrm{Au}$ nanoparticles of size $3.5 \mathrm{~nm}$ deposited by a solvothermal method, and further decorated with a $1.5 \mathrm{~nm}$ thin coating of CdS by UV-assisted deposition. ${ }^{53}$ The sandwiched Au nanoparticles act as the electron-transfer system, enabling efficient separation of charge carriers between $\mathrm{TiO}_{2}$ and CdS. Therefore, three component multi-junction systems are expected to show superior properties and performances to single or two component systems.

\subsection{Physicochemical properties and catalytic performance of Schottky-like materials}

The physicochemical properties such as morphology, and the structural, optical, and electrochemical properties of different Schottky-like materials are discussed and correlated to their catalytic performance, to understand the relationship between the properties of the materials and their enhanced catalytic behaviours.

\subsubsection{Conventional Schottky-like structures}

2.1.1.1 Ag/ZnO conventional structures. $\mathrm{ZnO}$ nanorods were fabricated by the sol-gel method followed by photo-reduction of $\mathrm{AgNO}_{3}$ solution to $\mathrm{Ag}$ nanoparticles on the tip of $\mathrm{ZnO}$ nanorods, leading to the formation of $\mathrm{Ag}$ decorated $\mathrm{ZnO}$ exhibiting Schottky-like properties (Table 1, entry 1). ${ }^{54}$ The adhesion between the $\mathrm{Ag}$ nanoparticles produced from the photo-reduction method and the photo-catalyst was weak as the reaction was not precisely controlled at the atomic level. The Ag incorporated $\mathrm{ZnO}$ nanorods showed intense optical absorption in the visible range from $400-700 \mathrm{~nm}$ due to the SPR effect of the Ag nanoparticles. ${ }^{54,55}$ Therefore, under visible light irradiation, the electrons generated on the surface of $\mathrm{Ag}$ due to the SPR effect migrated to the $\mathrm{CB}$ of $\mathrm{ZnO}$ and produced reactive oxygen species to mediate photo-catalytic activities. Meanwhile, under UV light irradiation, the $\mathrm{Ag} / \mathrm{ZnO}$ interface enabled the migration of photo-generated electrons from $\mathrm{ZnO}$ to the $\mathrm{Ag}$ nanoparticles, acting as an electron sink, thus leading to enhanced charge separation and photo-catalytic performance compared to bare $\mathrm{ZnO}$ nanorods. ${ }^{54}$ The kinetic constant of the photo-catalytic degradation of $\mathrm{MB}$ dye using $\mathrm{Ag} / \mathrm{ZnO}$ nanorods was $7.6 \times 10^{-3} \mathrm{~min}^{-1}$, while bare $\mathrm{ZnO}$ nanorods showed a degradation kinetic constant of $5.5 \times 10^{-3} \mathrm{~min}^{-1}$.

2.1.1.2 $\mathrm{M} / \mathrm{TiO}_{2}$ conventional structures $(\mathrm{M}=\mathrm{Ag}, \mathrm{Au})$. A conventional Schottky-like $\mathrm{Ag} / \mathrm{TiO}_{2}$ structure was fabricated by synthesising $\mathrm{TiO}_{2}$ microspheres by a solvothermal method and further decorating them with $\mathrm{Ag}$ nanoparticles by photoreduction (Table 1 , entry 2). ${ }^{56}$ The $\mathrm{TiO}_{2}$ microspheres showed a slight decrease in SSA from 159 to $135 \mathrm{~m}^{2} \mathrm{~g}^{-1}$ upon incorporation of $\mathrm{Ag}$ nanoparticles, which tend to occupy the pores of the catalyst in a random distribution in conventional Schottky-like structures. ${ }^{56}$ However, many studies also revealed an increase in the surface area when semiconducting materials are modified with metal nanoparticles. For instance, $\mathrm{Ag}$ decorated $\mathrm{ZnO}$ photocatalysts synthesised by a hydrothermal method showed

Table 1 Physicochemical properties and the pollutant removal efficiency of photocatalytic Schottky-like materials

\begin{tabular}{|c|c|c|c|c|c|c|c|c|c|}
\hline Entry & $\begin{array}{l}\text { Schottky-like } \\
\text { structure }\end{array}$ & Type & $\begin{array}{l}\text { Fabrication } \\
\text { technique }\end{array}$ & $\begin{array}{l}\text { Specific surface } \\
\text { area (SSA) } \\
\left(\mathrm{m} 2 \mathrm{~g}^{-1}\right)\end{array}$ & Band-gap (eV) & $\begin{array}{l}\text { Photocurrent } \\
\text { density } \\
\left(\mathrm{mA} \mathrm{cm}{ }^{-2}\right)\end{array}$ & Target pollutant $\left(\mathrm{mg} \mathrm{L}^{-1}\right)$ & $\begin{array}{l}\text { Kinetic } \\
\text { constant }(k) \\
\left(10^{-3} \min ^{-1}\right)\end{array}$ & Ref. \\
\hline 1 & $\mathrm{Ag} / \mathrm{ZnO}$ & Conventional & $\begin{array}{l}\text { Sol-gel and } \\
\text { photo-reduction }\end{array}$ & - & 3.37 & - & Methylene blue, (2) & 7.6 & 54 \\
\hline 2 & $\mathrm{Ag} / \mathrm{TiO}_{2}$ & Conventional & $\begin{array}{l}\text { Solvothermal } \\
\text { photo-reduction }\end{array}$ & 135 & 2.78 & - & Rhodamine B, (10) & 16.1 & 56 \\
\hline 3 & $\mathrm{Au} / \mathrm{TiO}_{2}$ & Conventional & Sol-gel & - & 3.20 & - & Methylene blue, (10) & 16.1 & 59 \\
\hline 4 & $\mathrm{Au} / \mathrm{CdS}$ & Core-shell & Solvothermal & - & - & $7 \times 10^{-3}$ & Rhodamine B, (0.35) & 26 & 62 \\
\hline 5 & $\mathrm{Zn} / \mathrm{SiO}_{2}$ & Core-shell & Sol-gel & 36 & 3.0 & - & Methyl violet, (3.5) & 9.5 & 65 \\
\hline 6 & $\begin{array}{l}\mathrm{Zn}-\mathrm{Fe}_{2} \mathrm{O}_{4} / \\
\mathrm{ZnO}\end{array}$ & Core-shell & Sol-gel & & 1.8 & - & Methylene blue, (10) & 8.5 & 66 \\
\hline 7 & $\mathrm{Bi} / \mathrm{g}-\mathrm{C}_{3} \mathrm{~N}_{4}$ & Nanosheets & $\begin{array}{l}\text { Polymerization } \\
\text { and } \\
\text { hydrothermal }\end{array}$ & 57 & - & - & Nitric oxide, (0.6) & 120 & 67 \\
\hline 8 & $\mathrm{Bi} / \mathrm{ZnwO}_{4}$ & Nanosheets & Solvothermal & 30 & - & $1.25 \times 10^{-3}$ & Nitric oxide, (0.4) & 67 & 68 \\
\hline 9 & $\mathrm{CdS} / \mathrm{Ag} / \mathrm{TiO}_{2}$ & Multi-junction & Hydrothermal & 386 & 1.57 & 6 & Nitrobenzene, (30) & 20 & 69 \\
\hline 10 & $\mathrm{CdS} / \mathrm{Au} / \mathrm{ZnO}$ & Multi-junction & $\begin{array}{l}\text { Hydrothermal } \\
\text { and pulse laser }\end{array}$ & - & - & 4.5 & Methylene blue, (0.3) & 13.3 & 70 \\
\hline
\end{tabular}


a SSA of $18 \mathrm{~m}^{2} \mathrm{~g}^{-1}$, higher than the SSA of bare $\mathrm{ZnO}\left(14 \mathrm{~m}^{2} \mathrm{~g}^{-1}\right) .^{57}$ Another demonstration of $\mathrm{Ag}$ loaded $\mathrm{ZnO}$ micro-flowers prepared by hydrothermal method showed a SSA of $5.8 \mathrm{~m}^{2} \mathrm{~g}^{-1}$, exhibiting no evident change compared to bare $\mathrm{ZnO}$ with a SSA of $5.7 \mathrm{~m}^{2} \mathrm{~g}^{-1} .^{58}$ The variation in the trend of surface area may be dependent on different methods of synthesis and processes. ${ }^{34}$ The band-gap of the $\mathrm{Ag} / \mathrm{TiO}_{2}$ underwent a red shift and was reduced to $2.2 \mathrm{eV}$ due to typical band alignment causing band bending in Schottky-like structures (Table 1 , entry 2). ${ }^{56} \mathrm{Ag} / \mathrm{TiO}_{2}$ supported the photo-catalytic degradation of Rhodamine $\mathrm{B}$, leading to a kinetic constant of $16 \times 10^{-3} \mathrm{~min}^{-1}$, while bare $\mathrm{TiO}_{2}$ microspheres exhibited a lower catalytic efficiency with a kinetic constant of $5 \times 10^{-3} \mathrm{~min}^{-1}$. $^{5}$

Conventional Schottky-like $\mathrm{Au} / \mathrm{TiO}_{2}$ structures were synthesized by the sol-gel method (Table 1 , entry 3$)^{59}$ and the impact of the variation of the $\mathrm{Au}$ nanoparticles size distribution over the catalytic properties of the materials was investigated. The $\mathrm{Au} / \mathrm{TiO}_{2}$ structures with $\mathrm{Au}$ nanoparticles of size $15 \mathrm{~nm}$ exhibited maximum photocatalytic efficiency for the degradation of methylene blue $(\mathrm{MB})$ with a kinetic constant of $16.1 \times$ $10^{-3} \mathrm{~min}^{-1}$. Smaller $(5 \mathrm{~nm}) \mathrm{Au}$ nanoparticles anchored on $\mathrm{TiO}_{2}$ nanospheres, exhibited a lower photocatalytic performance with a kinetic constant of $10.5 \times 10^{-3} \mathrm{~min}^{-1}$. The smallest metal nanoparticles $(<5 \mathrm{~nm})$ showed transitioning from metallic to molecular electronic states due to the quantum confinement effect, which in turn affected the charge transfer and separation abilities, thus lowering the catalytic activity. ${ }^{60}$ Nevertheless, the $\mathrm{Au} / \mathrm{TiO}_{2}$ structures with larger sized $\mathrm{Au}$ nanoparticles $(30 \mathrm{~nm})$ exhibited a lower photocatalytic efficiency for the degradation of $\mathrm{MB}$ with a kinetic constant of $4 \times 10^{-3} \mathrm{~min}^{-1}$ due to the poor contact with the surface of $\mathrm{TiO}_{2}$, leading to a lower catalytic performance. ${ }^{59,61}$ Therefore, the performance of the Schottky-like structures appeared to be highly dependent on the shape and size of metal nanoparticles and the contact at the metal and semiconductor interface. ${ }^{59,60}$

\subsubsection{Core-shell Schottky-like structures}

2.1.2.1 $\mathrm{Au} / \mathrm{CdS}$. A core-shell Schottky-like structure comprising $\mathrm{Au}$ metal nanoparticles as the core and CdS nanocrystals surrounding the Au metal, was synthesised by a wet-chemical and precisely controlled hydrothermal route (Table 1, entry 4). ${ }^{62}$ The CB of CdS is at $-1 \mathrm{eV}$ and the Fermi energy of Au nanoparticles is set at a less negative potential of $+0.5 \mathrm{eV}$. Therefore, the Au metal acts as a good electron scavenger, leading to the storage of electrons on the Au metal and the formation of a Schottky-like barrier at the junction. ${ }^{62}$ The coreshell $\mathrm{Au} / \mathrm{CdS}$ exhibited an almost two times higher transient photocurrent density of $7 \mu \mathrm{A} \mathrm{cm}^{-2}$ than pristine CdS and degraded the rhodamine B solution with a kinetic constant of $26 \times 10^{-3} \min ^{-1}$ (Table 1 , entry 4 ). ${ }^{62}$ As the thickness of the CdS shell increased from 9 to $18 \mathrm{~nm}$, the kinetic constant of photocatalytic degradation also increased from 26 to $60 \times$ $10^{-3} \min ^{-1}$ due to an increase of the charge carriers and electron transfer rate within the thicker shell. Another study exhibiting an increase of the CdS outer shell thickness by electrochemical deposition on Au inner metal core showed a sudden rise and fall of photocatalytic performance. When the
CdS thickness increased from 1 to $7 \mathrm{~nm}$, a spike in the photocurrent density to $75 \mu \mathrm{A} \mathrm{cm} \mathrm{cm}^{-2}$ was observed. Further increase of CdS thickness to $12 \mathrm{~nm}$ led to up to 2 times decrease of the photocurrent density. ${ }^{63}$ The increased shell thickness may attenuate the light absorption capacity of the semiconducting materials, which further deteriorates the production of hot electrons. ${ }^{64}$ Moreover, the increased shell thickness also leads to an increase in the distance between the photo-generated hot electrons on the surface of the outer shell and the inner metal core, resulting in more recombination of electron and hole pairs, hence reduced photocurrent density and photocatalytic performance. $^{64}$

2.1.2.2 $\mathrm{Zn} / \mathrm{M}_{x} \mathrm{O}_{x}\left(\mathrm{M}_{x} \mathrm{O}_{x}=\mathrm{SiO}_{2}, \mathrm{Fe}_{2} \mathrm{O}_{3}\right)$. Another core-shell structure involving $\mathrm{Zn}$ metal encapsulated by the $\mathrm{SiO}_{2}$ shell was fabricated by the sol-gel method (Table 1, entry 5). ${ }^{65}$ The band-gap of pristine $\mathrm{SiO}_{2}$ materials is generally very high, about $5.2 \mathrm{eV}$, and unsuitable for light harvesting activities. However, the core-shell $\mathrm{Zn} / \mathrm{SiO}_{2}$ structures showed significant redshifting of the band-gap to $3.0 \mathrm{eV}$ due to band bending of the $\mathrm{CB}$ of $\mathrm{SiO}_{2}$ to the Fermi level of $\mathrm{Zn}$ metal, enabling the composite material to absorb light at a lower energy, suitable for photocatalytic applications. ${ }^{65} \mathrm{Zn} / \mathrm{SiO}_{2}$ also exhibited a higher SSA $\left(32 \mathrm{~m}^{2} \mathrm{~g}^{-1}\right)$, compared to bare $\mathrm{SiO}_{2}\left(12 \mathrm{~m}^{2} \mathrm{~g}^{-1}\right)$, which facilitates the core shell structure towards adsorption and mass transfer of reactant molecules such as reactive oxygen species. ${ }^{65}$ Therefore, the photocatalytic degradation of methyl violet dye using $\mathrm{Zn} / \mathrm{SiO}_{2}$ showed a kinetic constant of $11.6 \times$ $10^{-3} \mathrm{~min}^{-1}$, about two times higher than that of pristine $\mathrm{SiO}_{2}$ $\left(5.1 \times 10^{-3} \mathrm{~min}^{-1}\right) .{ }^{65}$

A magnetic core-shell Schottky-like material was fabricated by incorporating a magnetite core of $\mathrm{Zn}-\mathrm{Fe}_{2} \mathrm{O}_{4}$ synthesised by hydrothermal method, followed by the immobilization of a $\mathrm{ZnO}$ shell on the surface (Table 1 , entry 6). ${ }^{66}$ The $\mathrm{Zn}-\mathrm{Fe}_{2} \mathrm{O}_{4} / \mathrm{ZnO}$ catalyst can be magnetically separated after every use due to the presence of the magnetite core, which enhanced the reusability of the catalyst. The magnetite core also enabled visible light activation of the composite catalyst as the band-gap of the core shell $\mathrm{Zn}-\mathrm{Fe}_{2} \mathrm{O}_{4} / \mathrm{ZnO}$ was reduced to $1.8 \mathrm{eV}$, compared to the band-gap of $\mathrm{ZnO}(3.2 \mathrm{eV}){ }^{66}$ Therefore, $\mathrm{Zn}-\mathrm{Fe}_{2} \mathrm{O}_{4} / \mathrm{ZnO}$ led to the photocatalytic degradation of MB dye with a kinetic constant of $8.5 \times 10^{-3} \mathrm{~min}^{-1}$ under the irradiation of visible light. ${ }^{66}$

\subsubsection{D nanosheet Schottky-like structures}

2.1.3.1 Bi/M $M_{x} O_{x}\left(M_{x} O_{x}=g-C_{3} N_{4}, Z n w O_{4}\right) .2 \mathrm{D} \quad \mathrm{Bi} / g-\mathrm{C}_{3} \mathrm{~N}_{4}$ nanosheet Schottky-like structures were fabricated by synthesizing $\mathrm{g}-\mathrm{C}_{3} \mathrm{~N}_{4}$ nanosheets under high temperature conditions by polymerization of urea and further decorating them with $\mathrm{Bi}$ nanospheres in an autoclave by the hydrothermal method (Table 1, entry 7). ${ }^{67}$ The TEM micrographs of $\mathrm{Bi} / \mathrm{g}-\mathrm{C}_{3} \mathrm{~N}_{4}$ nanosheets suggest a close contact between the metal and the semiconducting material, leading to the favourable transfer mechanism of photo-generated charge carriers at the interface. ${ }^{67}$ The $\mathrm{CB}$ of $\mathrm{g}-\mathrm{C}_{3} \mathrm{~N}_{4}$ is at a negative potential of $-1.12 \mathrm{eV}$, while the Fermi energy of $\mathrm{Bi}$ became less negative at $-0.17 \mathrm{eV}$. This trend allowed the flow of electrons from the $\mathrm{CB}$ of $\mathrm{g}-\mathrm{C}_{3} \mathrm{~N}_{4}$ to the Fermi level of $\mathrm{Bi}$ metal, making this 
structure a good electron sink to carry efficient charge separation. ${ }^{67}$ Pristine $g-\mathrm{C}_{3} \mathrm{~N}_{4}$ nanosheets led to the degradation of NO with a kinetic constant of $75 \times 10^{-3} \mathrm{~min}^{-1}$. 2D Bi/g- $\mathrm{C}_{3} \mathrm{~N}_{4}$ nanosheets exhibited high photocatalytic efficiency towards the removal of NO with a kinetic constant of $120 \times 10^{-3} \mathrm{~min}^{-1}$, showing an enhancement in the catalytic performance by a factor of $1.7 .^{67}$

The anchoring of $\mathrm{Bi}$ metal onto the surface of $\mathrm{ZnWO}_{4}$ microspheres, synthesised by the solvo-thermal method, was also demonstrated (Table 1, entry 8). ${ }^{68}$ The formation of Schottky-like structures between $\mathrm{Bi}$ and $\mathrm{ZnWO}_{4}$ enhanced the transient photocurrent density from 0.3 to $1.2 \mu \mathrm{A} \mathrm{cm}^{-2}$ and led to photocatalytic degradation of $\mathrm{NO}$ with a higher kinetic constant of $67 \times 10^{-3} \mathrm{~min}^{-1}$ than those of bare $\mathrm{ZnWO}_{4}(6 \times$ $\left.10^{-3} \mathrm{~min}^{-1}\right)$ and $\mathrm{Bi}\left(27 \times 10^{-3} \mathrm{~min}^{-1}\right) .{ }^{68}$ The abundant availability and low cost of Bi metal also makes it a good substitute for noble metals such as $\mathrm{Ag}$ and $\mathrm{Au}$ to develop Schottky-like junctions with semiconducting materials. ${ }^{67}$

\subsubsection{Multi-junction Schottky-like structures}

2.1.4.1 $\mathrm{CdS} / \mathrm{M} / \mathrm{M}_{x} \mathrm{O}_{x}\left(\mathrm{M}=\mathrm{Ag}, \mathrm{Au}\right.$ and $\left.\mathrm{M}_{x} \mathrm{O}_{x}=\mathrm{TiO}_{2}, \mathrm{ZnO}\right)$. The coupling of semiconductor/metal/semiconductor leads to the development of multi-junction Schottky-like structures. The formation of multi-junction Schottky-like structures by decorating $\mathrm{TiO}_{2}$ nanorods with $\mathrm{Ag}$ nanoparticles, followed by the deposition of a CdS coating via hydrothermal synthesis was demonstrated (Table 1, entry 9). ${ }^{69}$ The entrapment of $\mathrm{Ag}$ nanoparticles between the $\mathrm{TiO}_{2}$ and CdS coatings was confirmed from TEM micrographs. ${ }^{69}$ The photo-generated electrons start to migrate from the $\mathrm{CB}$ of $\mathrm{CdS}(-0.7 \mathrm{eV})$ located at a more negative potential $v s$. NHE (normal hydrogen electrode), than the $\mathrm{CB}$ of $\mathrm{TiO}_{2}(-0.3 \mathrm{eV})$ via the sandwiched $\mathrm{Ag}$ nanoparticles to $\mathrm{TiO}_{2}$ nanorods and undergo recombination reactions with the holes present at the $\mathrm{VB}$ of $\mathrm{TiO}_{2}$. The flux of electrons creates a Schottky-like barrier at the interfaces, leading to the concentration of holes on the surface of the CdS, and electrons on $\mathrm{TiO}_{2}$ nanorods. Therefore, the relay of electrons in the multi-junction structures from the CdS layer to $\mathrm{Ag}$ metal and then to the $\mathrm{TiO}_{2}$ nanorods leads to efficient charge separation and hence an enhanced transient photocurrent density of $4.3 \mathrm{~mA} \mathrm{~cm}{ }^{-2}$. The multi-junction $\mathrm{TiO}_{2} / \mathrm{Ag} / \mathrm{CdS}$ also exhibited band bending with an effective band-gap of $1.56 \mathrm{eV}$, much lower than those of pristine $\mathrm{TiO}_{2}(3.2 \mathrm{eV})$ and $\mathrm{CdS}(2.5 \mathrm{eV})$, enabling visible light activation of the composite material. Therefore, the photocatalytic degradation of nitrobenzene under visible light by the $\mathrm{TiO}_{2} / \mathrm{Ag} / \mathrm{CdS}$ multi-junction structure showed a kinetic constant of $16 \times 10^{-3} \mathrm{~min}^{-1}$, which is at least two times higher than that for pristine $\mathrm{TiO}_{2}$ and CdS. ${ }^{69}$

The fabrication of multi-junction structures between CdS/ $\mathrm{Au} / \mathrm{ZnO}$ (Table 1, entry 10), in which $\mathrm{ZnO}$ nanorods were deposited on the ITO (Indium Tin Oxide) substrate by a hydrothermal method followed by the deposition of Au and CdS on the surface of $\mathrm{ZnO}$ by pulse laser ablation, was also demonstrated. The ablation of the Au target by pulse laser deposited about $10 \mathrm{~nm}$ sized Au nanoparticles and the CdS target deposited a $25 \mathrm{~nm}$ thick coating of CdS on the $\mathrm{Au}$ decorated $\mathrm{ZnO}$ nanorods. The multi-junction structures of $\mathrm{CdS} / \mathrm{Au} / \mathrm{ZnO}$ improved the electron flux and separation of photo-generated charge carriers in a similar mechanism described above, leading to a high transient photocurrent density of $4.5 \mathrm{~mA} \mathrm{~cm}{ }^{-2}$, compared to the single junction structures between $\mathrm{CdS} / \mathrm{ZnO}$ $\left(1.5 \mathrm{~mA} \mathrm{~cm}^{-2}\right)$ and $\mathrm{Au} / \mathrm{ZnO}\left(0.05 \mathrm{~mA} \mathrm{~cm}^{-2}\right)$. The kinetic constant for the photocatalytic degradation of the MB dye using multi-junction Schottky-like CdS/Au/ZnO nanorods was $13.3 \times$ $10^{-3} \mathrm{~min}^{-1}$, higher than those of CdS/ZnO $\left(10.3 \times 10^{-3} \mathrm{~min}^{-1}\right)$ and $\mathrm{Au} / \mathrm{ZnO}\left(9.2 \times 10^{-3} \mathrm{~min}^{-1}\right)$.

\subsection{Concluding remarks and strategies for improving Schottky-like materials}

To conclude, several fabrication routes and photo-catalytic applications of Schottky-like nanostructures of various shapes, sizes and compositions have been investigated. Conventional Schottky-like materials exhibited a lower catalytic efficiency for the degradation of pollutant molecules such as methylene blue and rhodamine $\mathrm{B}$ dyes with kinetic constants in the range of 7.6-16 $\times 10^{-3} \mathrm{~min}^{-1}$ due to poor contact at the interface and uncontrolled synthesis causing agglomeration of metal nanoparticles on the surface of semiconducting materials. The coreshell structures provide close contact at the metal/semiconductor junctions, leading to an efficient charge transfer across the materials and hence enhancing the catalytic degradation of dyes such as methylene blue with kinetic constants in the range of $8.5-26 \times 10^{-3} \mathrm{~min}^{-1}$. 2D nanosheets offer superior chemically active facets and edges, and enhanced surface area, leading to enhanced photo-electrochemical properties due to which the catalytic efficiency of the materials for the degradation of gaseous pollutants responsible of ozone depletion such as nitric oxide gas is higher than that of any other Schottky-like nanostructures with kinetic constants in the range of $60-120$ $\times 10^{-3} \mathrm{~min}^{-1}$. The multi-junction Schottky-like materials allow greater charge separation than any other structures as the sandwiched metal nanoparticles act as an electron mediator, leading to a suppressed recombination rate and enhanced catalysis of pollutants such as methylene blue with kinetic constants in the range of $13-20 \times 10^{-3} \mathrm{~min}^{-1}$. Challenges related to the synthesis of materials used for conventional Schottky-like structures remain primarily related to the agglomeration of metal nanoparticles in solution, leading to reduced catalytic efficiency. The development of core-shell and multijunction Schottky structures was found to limit or prohibit agglomeration and therefore improve processability. The encapsulation or sandwiching of metal nanoparticles at the nanoscale with appropriate semiconducting materials is a particularly promising approach that benefits from the enhanced charge transfers at the interfaces, but yet requires complex synthesis procedures. The fabrication of Schottky-like materials, however, mostly employs the use of noble metals such as $\mathrm{Au}, \mathrm{Ag}$, and Pt to couple with semiconducting materials, which are present in scare quantity in nature and are also very costly. The use of conductive non-noble metals or alloys such as stainless steel needs to be explored towards the next generation of more scalable Schottky-like materials. 


\section{Types, configuration and charge separation mechanism of heterojunctions}

The charge carrier dynamics of the semiconductor/semiconductor heterojunction involves the creation of a space-charge region at the interface of the semiconducting materials from the migration of charge carriers. ${ }^{71}$ The diffusion of electron and hole pairs across the space charge region generates an internal electric field, which in turn directs the electrons and holes to travel in the opposite direction. ${ }^{72}$ This leads to the separation of charge carriers as electrons get transferred to the CB of the semiconductor with a higher reduction potential, while the holes get transferred to the $\mathrm{VB}$ of the semiconductor with a high oxidation potential. ${ }^{10,72}$ Therefore, the charge carrier dynamics of the heterojunction materials leads to more effective charge separation, rapid charge transfer mechanism, and improved lifetime of the electron and hole pairs, leading to enhancement of the photocatalytic efficiency.

Conventional heterojunction structures are classified into four main categories, including type-I, type-II, type-III, and direct Z-scheme, defined based on the respective alignment of the conduction band (CB) and the valence band (VB). ${ }^{19,73}$ In a type-I heterojunction, the CB and VB of the semiconductor material A will be higher and lower, respectively, than the bands of semiconductor $\mathrm{B}$; therefore, the accumulation of electrons and holes will only occur at the $\mathrm{CB}$ and $\mathrm{VB}$, respectively, of the semiconductor B, as shown in Fig. 4(A). ${ }^{1}$ The accumulation of both electrons and holes occurs on the same semiconductor material in type-I heterojunction; therefore, such separation of charges is not highly effective as charge carriers can still undergo fast recombination. ${ }^{1}$

In type-II heterojunctions, both $\mathrm{CB}$ and $\mathrm{VB}$ of semiconductor A will be higher than those of semiconductor B (Fig. 4(B)). ${ }^{74}$ Type-II heterojunctions therefore allow for the accumulation of electrons across the $\mathrm{CB}$ of semiconductor $\mathrm{B}$, while holes will accumulate at the VB of semiconductor A, hence leading to very efficient charge separation. ${ }^{74}$ Although type-III heterojunctions are similar to type-II, both CB and VB in semiconductor A will be higher compared to semiconductor $\mathrm{B}$, putting the bands very far apart and thereby preventing direct overlap, which is not suitable for mediating the spatial separation of electron and hole pairs (Fig. 4(C)). ${ }^{75}$ Type-II heterojunctions have been deemed the most suitable metastable structures for semiconducting applications, and have been explored for a range of catalytic reaction control. ${ }^{19}$ However, type II heterojunctions also possess a major inadequacy from the thermodynamic perspective as improved charge separation efficiency does not compensate the reduced redox ability of the semiconducting materials, desirable for photocatalytic applications. ${ }^{76}$ The type II heterojunction materials allow the accumulation of photogenerated electrons and holes on semiconducting materials with weak reduction potential and weak oxidation potential, respectively. ${ }^{77}$ This kind of charge separation impairs the involvement of charge carriers in catalytic reactions. The electrostatic attraction between opposite charge-carriers in a semiconducting material, concurrently inhibits the flow of electrons from one semiconductor to the other semiconductor in type II
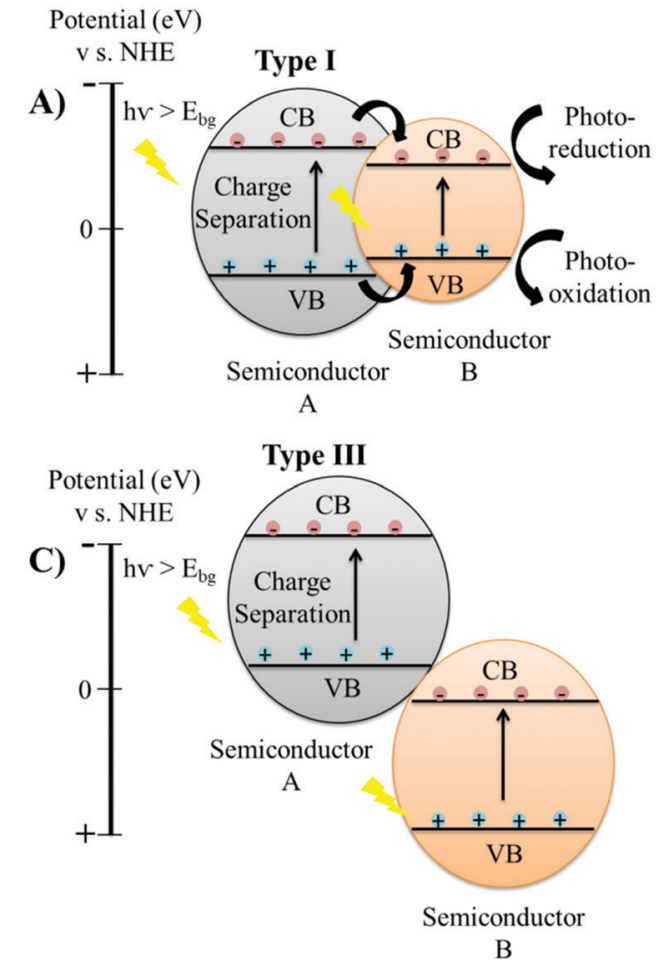

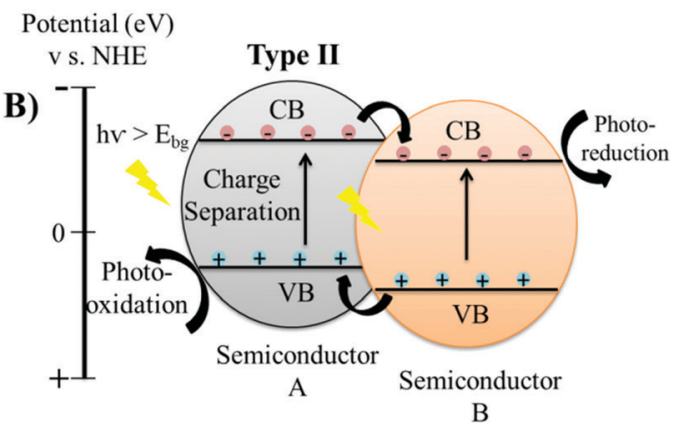

Potential (eV) v s. NHE D) Direct Z-Scheme

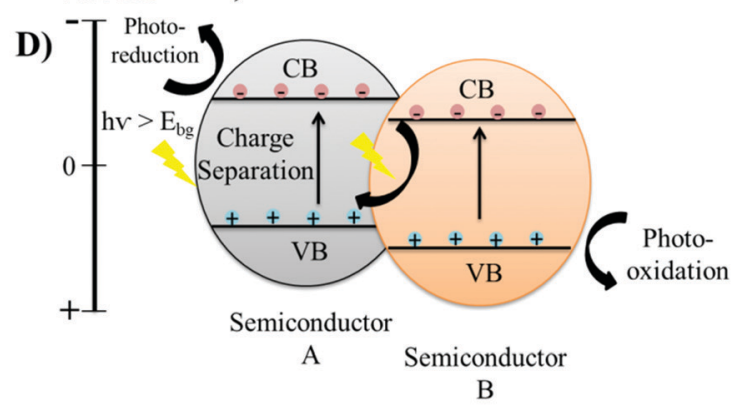

Fig. 4 Spatial arrangements of different heterojunction structures: (A) type I; (B) type II; (C) type III and (D) direct Z scheme. 
heterojunction structures. ${ }^{78}$ Therefore, the theoretical charge transfer mechanism of a atype II heterojunction is difficult to realize because the electrostatic repulsive forces are great enough to suspend the flux of photo-generated charge carriers. Besides this, the charge transfer mechanism also leads to the reduction of the overall redox ability of type II heterojunctions.

The direct Z-scheme heterojunction shows a similar band alignment to that of type-II heterojunctions, but the direction of charge is opposite (Fig. 4(D)). ${ }^{79}$ Direct Z-scheme heterojunctions are also termed as S-scheme heterojunctions. ${ }^{80} \mathrm{~A}$ direct $\mathrm{Z}$ scheme heterojunction consists of staggered band alignment, with charge transfer mechanism completely different from that of a type II heterojunction. ${ }^{79,81}$ The photo-generated electrons in the conduction band of the semiconducting material with a high reduction potential (semiconductor B) and holes in the valence band of the semiconducting material with a high oxidation potential (semiconductor A) are reserved for photocatalytic reactions. ${ }^{79}$ When two semiconductors come in close contact, initially the diffusion of electrons occur from semiconductor B possessing a high reduction potential to semiconductor A with a high oxidation potential. ${ }^{82}$ This creates a depletion region at the interface on the side of semiconductor $B$ and an accumulation region on the side of semiconductor $A$, due to which the semiconductors A and B become negatively and positively charged, respectively. This internally generated electric field leads to the acceleration of photo-generated electrons from the $\mathrm{CB}$ of semiconductor $\mathrm{A}$ to the $\mathrm{VB}$ of semiconductor $\mathrm{B}$, opposite to the charge transfer mechanism of type II heterojunctions. Moreover, close contact of the two semiconductors aligns the Fermi energy of each semiconductor to the same level leading to band bending. ${ }^{82}$ Band bending further supports the flux of electrons from the $\mathrm{CB}$ of semiconductor $\mathrm{A}$ to the $\mathrm{VB}$ of semiconductor $\mathrm{B} .{ }^{83}$ Therefore, physical factors such as an internal electric field, band bending and coulombic forces drive the recombination of less powerful electrons from the $\mathrm{CB}$ of semiconductor $\mathrm{A}$ with a lower reduction potential to the inadequate holes present in the VB of semiconductor B with a lower oxidation potential. ${ }^{84}$ Thus, the redox affinity of the direct Z-scheme/S-scheme is maintained as the charge transfer mechanism eliminates useless charge carriers and preserves the powerful photo-generated electrons and holes separately on semiconductor B and A, respectively. ${ }^{85}$ Therefore, the Z-scheme heterojunctions not only improve the separation of charge carriers by allowing partial recombination reactions but also retain the strong redox abilities of the separated electron and hole pairs. ${ }^{86}$

\subsection{Physicochemical properties and catalytic performance of heterojunctions}

The physicochemical properties of heterojunction materials are dependent on the materials and synthesis routes employed, which in turn dictate the overall catalytic efficiency of the heterojunctions. ${ }^{87}$ The correlation of material dependent physicochemical properties with catalytic performance of the heterojunctions is discussed in the following section.

\subsubsection{Type I heterojunctions}

3.1.1.1 $\mathrm{FeS}_{2} / \mathrm{g}-\mathrm{C}_{3} N_{4}$. A type I heterojunction between $\mathrm{FeS}_{2}$ and $\mathrm{g}-\mathrm{C}_{3} \mathrm{~N}_{4}$ was realised by calcination, liquid exfoliation and in situ deposition of $\mathrm{FeS}_{2}$ on $\mathrm{g}-\mathrm{C}_{3} \mathrm{~N}_{4}$ via the hot injection route (Table 2, entry 1). ${ }^{88}$ The $\mathrm{CB}$ and $\mathrm{VB}$ of $\mathrm{g}-\mathrm{C}_{3} \mathrm{~N}_{4}$ were -1.28 and $+1.62 \mathrm{eV}$, respectively vs. NHE. Similarly, $\mathrm{FeS}_{2}$ showed $\mathrm{CB}$ and $\mathrm{VB}$ at -0.5 and $+0.8 \mathrm{eV}$, respectively. Therefore, the photogenerated electrons were transferred from the $\mathrm{CB}$ of $\mathrm{g}-\mathrm{C}_{3} \mathrm{~N}_{4}$ to the $\mathrm{CB}$ of $\mathrm{FeS}_{2}$ and holes from the VB of $\mathrm{g}-\mathrm{C}_{3} \mathrm{~N}_{4}$ to the $\mathrm{VB}$ of $\mathrm{FeS}_{2}$, exhibiting a typical type I charge transfer mechanism. The TEM micrograph of $\mathrm{FeS}_{2} / \mathrm{g}_{-} \mathrm{C}_{3} \mathrm{~N}_{4}$ shown in Fig. 5(A), highlighted an intimate contact between $\mathrm{FeS}_{2}$ and $\mathrm{g}_{-}-\mathrm{C}_{3} \mathrm{~N}_{4}$ nanosheets, which facilitates charge mobility and separation in the hetero-structures. The SSA of the $\mathrm{FeS}_{2} / \mathrm{g}-\mathrm{C}_{3} \mathrm{~N}_{4}$ heterostructures reduced to $34.5 \mathrm{~m}^{2} \mathrm{~g}^{-1}$, compared to that of pristine

Table 2 Physicochemical properties and the pollutant removal efficiency of photocatalytic heterojunction materials

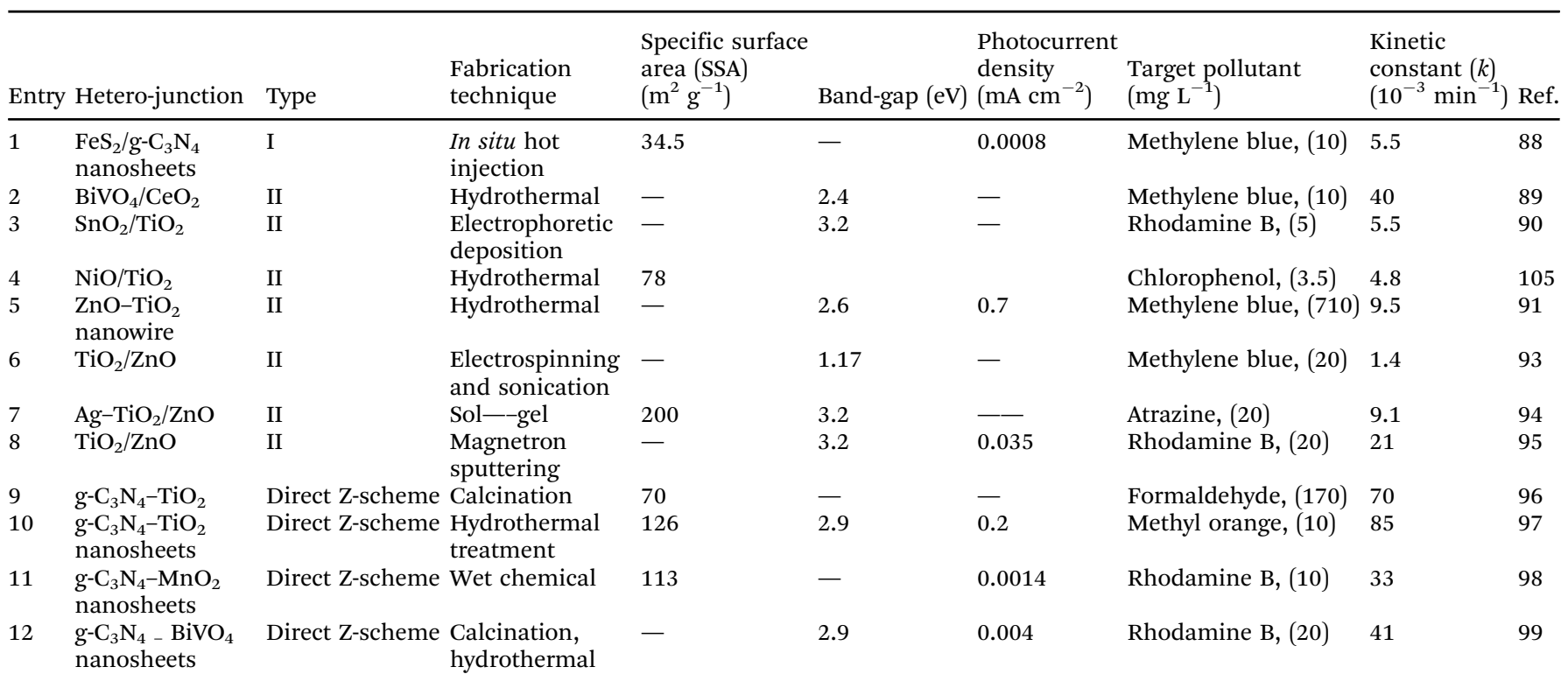


g- $\mathrm{C}_{3} \mathrm{~N}_{4}$ (48 $\left.\mathrm{m}^{2} \mathrm{~g}^{-1}\right)$, due to intimate integration of the nanosheets. ${ }^{88}$ The photo-current density of type- $1 \mathrm{FeS}_{2} / \mathrm{g}-\mathrm{C}_{3} \mathrm{~N}_{4}$ increased to $0.8 \times 10^{-3} \mathrm{~mA} \mathrm{~cm}{ }^{-1}$, while pristine $\mathrm{g}-\mathrm{C}_{3} \mathrm{~N}_{4}$ exhibited $0.4 \times 10^{-3} \mathrm{~mA} \mathrm{~cm}{ }^{-1}$. Type $\mathrm{I} \mathrm{FeS}_{2} / \mathrm{g}-\mathrm{C}_{3} \mathrm{~N}_{4}$ nanosheets led to degradation of $\mathrm{MB}$ solution at a kinetic constant of $5.5 \times 10^{-3} \mathrm{~min}^{-1}$.

\subsubsection{Type II heterojunctions}

3.1.2.1 $\mathrm{BiVO}_{4} / \mathrm{CeO}_{2}$. Similarly, a hydrothermal route was employed to synthesise $\mathrm{BiVO}_{4} / \mathrm{CeO}_{2}$ type II heterojunction structures, in which $\mathrm{BiVO}_{4}$ and $\mathrm{CeO}_{2}$ had different isoelectric points at $\mathrm{pH} 4.5$ and 7.3, respectively (Table 2, entry 2). $\mathrm{BiVO}_{4} /$ $\mathrm{CeO}_{2}$ enabled the photo-catalytic degradation of a mixture of methylene blue (MB) (cationic dye) and methyl orange (MO) (anionic dye) at a kinetic constant of $40 \times 10^{-3} \mathrm{~min}^{-1}$ (Table 2, entry 2). ${ }^{89}$ Otherwise, the surface charge of single $\mathrm{BiVO}_{4}$ would show electronic repulsion towards anionic dyes such as MO and single $\mathrm{CeO}_{2}$ would show electronic repulsion towards cationic dyes such as $\mathrm{MB}$, leading to no catalytic degradation. ${ }^{89}$ Therefore, fabrication of the heterojunction not only enhanced the catalytic efficacy by efficient charge separation but also influenced the absorption capabilities by overcoming the electronic repulsion between surface charges and the dye molecules. $^{89}$

3.1.2.2 $\mathrm{M}_{x} \mathrm{O}_{x} / \mathrm{TiO}_{2}\left(\mathrm{M}_{x} \mathrm{O}_{x}=\mathrm{SnO}_{2}, \mathrm{NiO}\right) . \mathrm{SnO}_{2} / \mathrm{TiO}_{2}$ type-II heterojunctions were prepared by electrophoretic-deposition of P-25 $\mathrm{TiO}_{2}$ on the surface of $\mathrm{SnO}_{2}$ coated glass, followed by annealing at various temperatures from $200-600{ }^{\circ} \mathrm{C} .{ }^{90}$ The kinetic constant of photo-catalytic degradation of rhodamine B using $\mathrm{SnO}_{2} / \mathrm{TiO}_{2}$ increased from 2 to $5.5 \times 10^{-3} \mathrm{~min}^{-1}$ (Table 2, entry 3 ) with an increase in the annealing temperature from 100 to $400{ }^{\circ} \mathrm{C}$ due to enhanced crystallinity and increased crystallite size from 21 to $39 \mathrm{~nm} .{ }^{90}$ A further increase in temperature to $600{ }^{\circ} \mathrm{C}$ led to the conversion of anatase to the rutile phase and aggregation of nanoparticles to form agglomerates of size up to $200 \mathrm{~nm}$, due to which the catalytic efficiency again decreased to $2.5 \times 10^{-3} \mathrm{~min}^{-1}$. $^{90}$

A hydrothermal synthesis route was exploited to develop flower-like type II NiO/ $\mathrm{TiO}_{2}$ heterojunction structures (Table 2, entry 4). The fabricated $\mathrm{NiO} / \mathrm{TiO}_{2}$ showed a high SSA of $78 \mathrm{~m}^{2} \mathrm{~g}^{-1}$ compared to pristine NiO $\left(28 \mathrm{~m}^{2} \mathrm{~g}^{-1}\right)$, leading to a greater number of photo-active sites for catalytic reactions along with an enhancement in the absorption capabilities of pollutant molecules on the surface of the catalyst. The photocatalytic degradation of $p$-chlorophenol using these $\mathrm{NiO} / \mathrm{TiO}_{2}$ hetero-structures showed a kinetic constant of $4.8 \times$ $10^{-3} \min ^{-1}$ (Table 2, entry 4), which was two times higher than that of pristine $\mathrm{NiO}$ and $\mathrm{TiO}_{2}$.

3.1.2.3 $\mathrm{TiO}_{2} / \mathrm{ZnO}$. A hydrothermal route was also used for the fabrication of type II $\mathrm{ZnO}-\mathrm{TiO}_{2}$ nanowires, in which $\mathrm{TiO}_{2}$ nanowires were synthesised by the hydrothermal method, followed by deposition of the $\mathrm{ZnO}$ layer via atomic layer deposition (Table 2, entry 5). ${ }^{91}$ The TEM micrograph of the ZnO- $\mathrm{TiO}_{2}$ nanowires shown in Fig. 5(B) highlights the deposition of $\mathrm{ZnO}(2.6 \mathrm{~nm})$ on the $\mathrm{TiO}_{2}$ nanowire. The transient photocurrent increased from 0.3 to $0.7 \mathrm{~mA} \mathrm{~cm}^{-2}$ in the $\mathrm{ZnO}-$ $\mathrm{TiO}_{2}$ nanowires compared to pristine $\mathrm{TiO}_{2}$ nanowires, which indicated less recombination of charge carriers and enhanced charge collection ability in the heterojunction structure. The optical band-gap associated with pristine $\mathrm{TiO}_{2}$ was 2.9 , while ZnO-TiO ${ }_{2}$ exhibited a band-gap of 2.6 , showing a significant
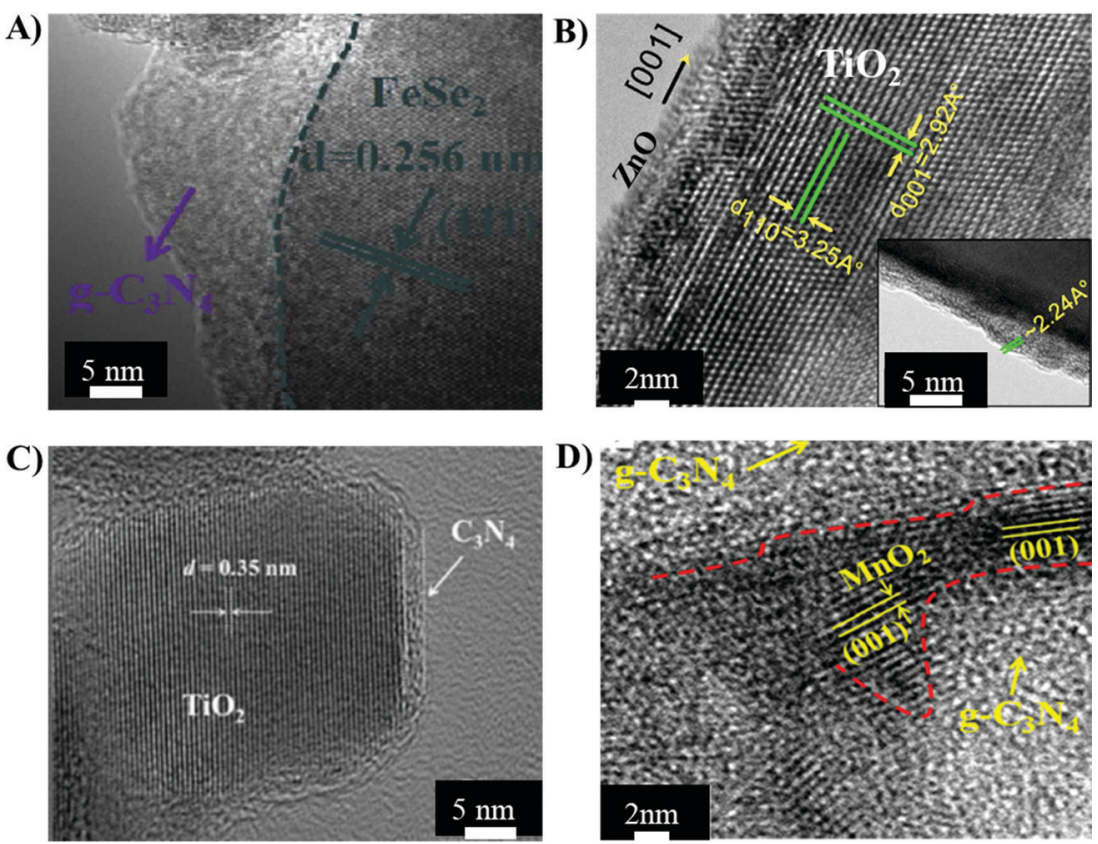

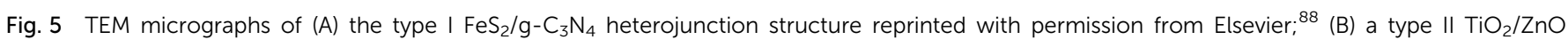

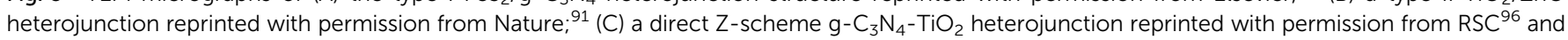
(D) a direct Z-scheme $\mathrm{g}-\mathrm{C}_{3} \mathrm{~N}_{4} / \mathrm{MnO}_{2}$ reprinted with permission from ACS publications. ${ }^{98}$ 
red-shift due to type II band alignments in the core-shell $\mathrm{ZnO}-$ $\mathrm{TiO}_{2}$ heterojunction structures and the quantum confinement effect exhibited by the ultrathin layer of $\mathrm{ZnO} .{ }^{91}$ The narrowing of the band-gap extended the light harvesting abilities of the heterojunctions towards visible light. ${ }^{3}$ The improved electronic and optical properties of the hetero-structures led to an enhancement of the photocatalytic efficiency. ${ }^{92}$ The photocatalysis of $\mathrm{MB}$ solution using $\mathrm{ZnO}-\mathrm{TiO}_{2}$ showed a kinetic constant of $9.5 \times 10^{-3} \mathrm{~min}^{-1}$, while pristine $\mathrm{TiO}_{2}$ nanowires degraded MB at a kinetic constant of $5.35 \times 10^{-3} \mathrm{~min}^{-1} .{ }^{91}$

$\mathrm{TiO}_{2}-\mathrm{ZnO}$ heterojunction structures fabricated by the electrospinning and calcination route led to a decrease in the bandgap to $1.17 \mathrm{eV}$, compared to pristine $\mathrm{TiO}_{2}$ with a $3.2 \mathrm{eV}$ bandgap (Table 2, entry 6). This decrease in band-gap enhanced light absorption and enabled photocatalytic degradation of the dye at lower energy irradiation with a kinetic constant value of $1.3 \times$ $10^{-3} \min ^{-1}$ under direct sunlight. ${ }^{93}$ However, no band-gap narrowing was observed when $\mathrm{Ag}$ doped $\mathrm{TiO}_{2} / \mathrm{ZnO}$ heterostructures were fabricated by a sol-gel route (Table 2, entry 7 ). $\mathrm{Ag}-\mathrm{TiO}_{2} / \mathrm{ZnO}$ exhibited a band-gap in the range of 3.2 to $3.3 \mathrm{eV}$, similar to the band-gap of pristine $\mathrm{TiO}_{2}$ and $\mathrm{ZnO}$ but Ag doping led to the absorption of visible light due to a localised SPR effect. A Xe lamp with a wavelength of $250-765 \mathrm{~nm}$ was employed to degrade atrazine using $\mathrm{Ag}-\mathrm{TiO}_{2} / \mathrm{ZnO}$ heterostructures. Therefore, the conjugation of the SPR effect at the metal/semiconductor junction in the visible region and Schottky-like barrier at the semiconductor/semiconductor interface led to the photo-catalytic degradation of atrazine solution with a kinetic constant of $9.1 \times 10^{-3} \mathrm{~min}^{-1}$ (Table 2, entry 7). ${ }^{94}$

The fabrication of $\mathrm{TiO}_{2} / \mathrm{ZnO}$ heterojunctions was also explored using magnetron sputtering techniques, ${ }^{95}$ which led to a deposition of $350 \mathrm{~nm}$ thick $\mathrm{ZnO}$ layer followed by a 120$200 \mathrm{~nm}$ thick $\mathrm{TiO}_{2}$ coating (Table 2, entry 8). The thicker coatings of $\mathrm{TiO}_{2}$ showed the presence of a high fraction of the rutile phase, which provided recombination centres for photo-generated electron and hole pairs, decreasing the separation efficiency and catalytic performance. Therefore, the photocurrent density of $\mathrm{TiO}_{2} / \mathrm{ZnO}\left(200 \mathrm{~nm} \mathrm{TiO}{ }_{2}\right.$ coating) also reduced to $0.01 \mathrm{~mA} \mathrm{~cm}^{-2}$, while the heterojunction with a $120 \mathrm{~nm}$ thick film of $\mathrm{TiO}_{2}$ exhibited a higher photocurrent of $0.35 \mathrm{~mA} \mathrm{~cm}{ }^{-2}$ and quickly degraded rhodamine $\mathrm{B}$ with a kinetic constant of $21 \times 10^{-3} \mathrm{~min}^{-1}$ (Table 2, entry 8 ).

\subsubsection{Direct-Z scheme heterojunctions}

3.1.3.1 $g-C_{3} N_{4}-M_{x} O_{x}\left(M_{x} O_{x}=T^{2} O_{2}, M_{n} O_{2}, B i V O_{4}\right)$. Direct- $Z$ scheme heterojunctions were developed by the calcination of a wet mixture of $\mathrm{P}-25 \mathrm{TiO}_{2}$ with urea, leading to the fabrication of $\mathrm{g}-\mathrm{C}_{3} \mathrm{~N}_{4}-\mathrm{TiO}_{2}$ for the degradation of formaldehyde (Table 2, entry 9). ${ }^{96}$ The TEM micrographs of g- $\mathrm{C}_{3} \mathrm{~N}_{4}-\mathrm{TiO}_{2}$ revealed a secondary phase of $\mathrm{g}-\mathrm{C}_{3} \mathrm{~N}_{4}$ layers covering the $\mathrm{TiO}_{2}$ granules, shown in Fig. 5(C), which indicated that g- $\mathrm{C}_{3} \mathrm{~N}_{4}$ did not get incorporated into the lattice but only covered the surface of $\mathrm{TiO}_{2}$. The anatase $\mathrm{TiO}_{2}$ exhibits the $\mathrm{CB}$ and $\mathrm{VB}$ positions at -0.24 and $2.9 \mathrm{eV} v s$. NHE, respectively. The $\mathrm{CB}$ and $\mathrm{VB}$ of $\mathrm{g}-\mathrm{C}_{3} \mathrm{~N}_{4}$ are at -0.85 and $1.85 \mathrm{eV} v s$. NHE, respectively. Therefore, the electrons migrate from the $\mathrm{CB}$ of $\mathrm{TiO}_{2}$ to the $\mathrm{VB}$ of $\mathrm{g}-\mathrm{C}_{3} \mathrm{~N}_{4}$ and undergo recombination reactions with the holes of g- $\mathrm{C}_{3} \mathrm{~N}_{4}$. Meanwhile, upon light irradiation, the electrons are transferred from the $\mathrm{VB}$ to the $\mathrm{CB}$ of $\mathrm{g}-\mathrm{C}_{3} \mathrm{~N}_{4}$ and the holes located at the $\mathrm{VB}$ of $\mathrm{TiO}_{2}$ do not leave their positions, leading to efficient charge separation. The rate constant of photocatalytic degradation of formaldehyde using Z-Scheme g- $\mathrm{C}_{3} \mathrm{~N}_{4}{ }^{-}$ $\mathrm{TiO}_{2}$ was $70 \times 10^{-3} \mathrm{~min}^{-1}$, about double that of pristine P-25 $\mathrm{TiO}_{2}\left(28 \times 10^{-3} \mathrm{~min}^{-1}\right)$. The degradation mechanism involved the photo-reduction of atmospheric $\mathrm{O}_{2}$ into superoxide ions $\left({ }^{\circ} \mathrm{O}_{2}{ }^{-}\right)$at the CB of $\mathrm{g}-\mathrm{C}_{3} \mathrm{~N}_{4}$ by localized electrons. The holes stored in the $\mathrm{VB}$ of $\mathrm{TiO}_{2}$ underwent a photo-oxidation reaction by reacting with $\mathrm{H}_{2} \mathrm{O}$ molecules to produce $\mathrm{OH}^{\bullet}$ radicals, which were responsible for oxidising the solution of formaldehyde.

If g- $\mathrm{C}_{3} \mathrm{~N}_{4}-\mathrm{TiO}_{2}$ formed a conventional type II heterojunction structure, then electrons from the $\mathrm{CB}$ of $\mathrm{g}-\mathrm{C}_{3} \mathrm{~N}_{4}$ would be transferred to the $\mathrm{CB}$ of $\mathrm{TiO}_{2}$ and holes would migrate from the $\mathrm{VB}$ of $\mathrm{TiO}_{2}$ to the $\mathrm{VB}$ of $\mathrm{g}^{-} \mathrm{C}_{3} \mathrm{~N}_{4}$. In this case, the holes localized at the $\mathrm{VB}$ of $\mathrm{g}-\mathrm{C}_{3} \mathrm{~N}_{4}$ would not react with water molecules to produce hydroxyl radicals because the $\mathrm{VB}$ position of $\mathrm{g}-\mathrm{C}_{3} \mathrm{~N}_{4}(1.85 \mathrm{eV})$ is higher than that of the $\mathrm{H}_{2} \mathrm{O} / \mathrm{OH}^{\bullet}$ couple $(2.7 \mathrm{eV})$ vs. NHE, which would result in a lower catalytic efficiency than that of pristine $\mathrm{TiO}_{2}$. Therefore, the heterojunction structure in this study between $\mathrm{g}-\mathrm{C}_{3} \mathrm{~N}_{4}$ and $\mathrm{TiO}_{2}$ was a direct Z-scheme, instead of type II. The charge transfer mechanism of $g-\mathrm{C}_{3} \mathrm{~N}_{4}-\mathrm{TiO}_{2}$ is also represented in Fig. 6(A). ${ }^{96}$

The fabrication of direct Z-scheme $\mathrm{g}-\mathrm{C}_{3} \mathrm{~N}_{4}-\mathrm{TiO}_{2}$ by a hydrothermal route (Table 2 , entry 10$),{ }^{97}$ which led to the photocatalytic degradation of methyl orange (MO) solution with a kinetic constant of $85 \times 10^{-3} \mathrm{~min}^{-1}$ was also demonstrated. The catalytic efficiency started to decrease with increasing the $\mathrm{g}-\mathrm{C}_{3} \mathrm{~N}_{4}$ content from 70 to $120 \mathrm{mg}$, as excessive dosage of $g-\mathrm{C}_{3} \mathrm{~N}_{4}$ led to a decrease in the redox capability of the heterostructure because of its low conductivity. ${ }^{97}$ Therefore, it is necessary to optimize the content of semiconducting materials in the hetero-structures for efficient charge separation and catalysis. ${ }^{97}$

Another direct Z-Scheme heterojunction was fabricated by coupling $\mathrm{g}-\mathrm{C}_{3} \mathrm{~N}_{4}$ and $\mathrm{MnO}_{2}$ by a wet-chemical method (Table 2, entry 11). ${ }^{98}$ The TEM micrograph presented in Fig. 5(D) shows the integration of $\mathrm{g}-\mathrm{C}_{3} \mathrm{~N}_{4}$ and $\mathrm{MnO}_{2}$. The $\mathrm{CB}$ and $\mathrm{VB}$ of $\mathrm{MnO}_{2}$ were at 1.22 and $3.5 \mathrm{eV}$, respectively and the $\mathrm{CB}$ and $\mathrm{VB}$ of the synthesised $\mathrm{g}-\mathrm{C}_{3} \mathrm{~N}_{4}$ were at -1.6 and $1.73 \mathrm{eV}$, respectively. Therefore, electrons generated on the $\mathrm{CB}$ of $\mathrm{MnO}_{2}$ moved to the $\mathrm{VB}$ of $\mathrm{g}-\mathrm{C}_{3} \mathrm{~N}_{4}$ and combined with the holes. ${ }^{98}$ The electrons on the $\mathrm{CB}$ of $\mathrm{g}-\mathrm{C}_{3} \mathrm{~N}_{4}$ reacted with $\mathrm{O}_{2}$ to form superoxide ions $\left({ }^{\bullet} \mathrm{O}_{2}{ }^{-}\right)$, while the holes present on $\mathrm{MnO}_{2}$ reacted with absorbed water molecules to produce hydroxyl radicals $\left(\mathrm{OH}^{\bullet}\right) .{ }^{98}$ The charge transfer mechanism of $\mathrm{g}-\mathrm{C}_{3} \mathrm{~N}_{4}-\mathrm{MnO}_{2}$ is also presented in Fig. 6(B). Efficient charge separation in the direct Z-scheme g- $\mathrm{C}_{3} \mathrm{~N}_{4} / \mathrm{MnO}_{2}$ heterojunction quickly degraded rhodamine $\mathrm{B}$ solution at a kinetic constant of $33 \times 10^{-3} \mathrm{~min}^{-1}$ (Table 2, entry 11). ${ }^{98}$

The formation of heterojunctions between $\mathrm{BiVO}_{4}$ and g- $\mathrm{C}_{3} \mathrm{~N}_{4}$ nanosheets also showed a direct Z-Scheme transfer mechanism (Table 2, entry 12), ${ }^{99}$ whereby the photo-generated electrons generated in the $\mathrm{CB}$ of $\mathrm{g}-\mathrm{C}_{3} \mathrm{~N}_{4}$ migrate to the $\mathrm{VB}$ of $\mathrm{BiVO}_{4}$ to 

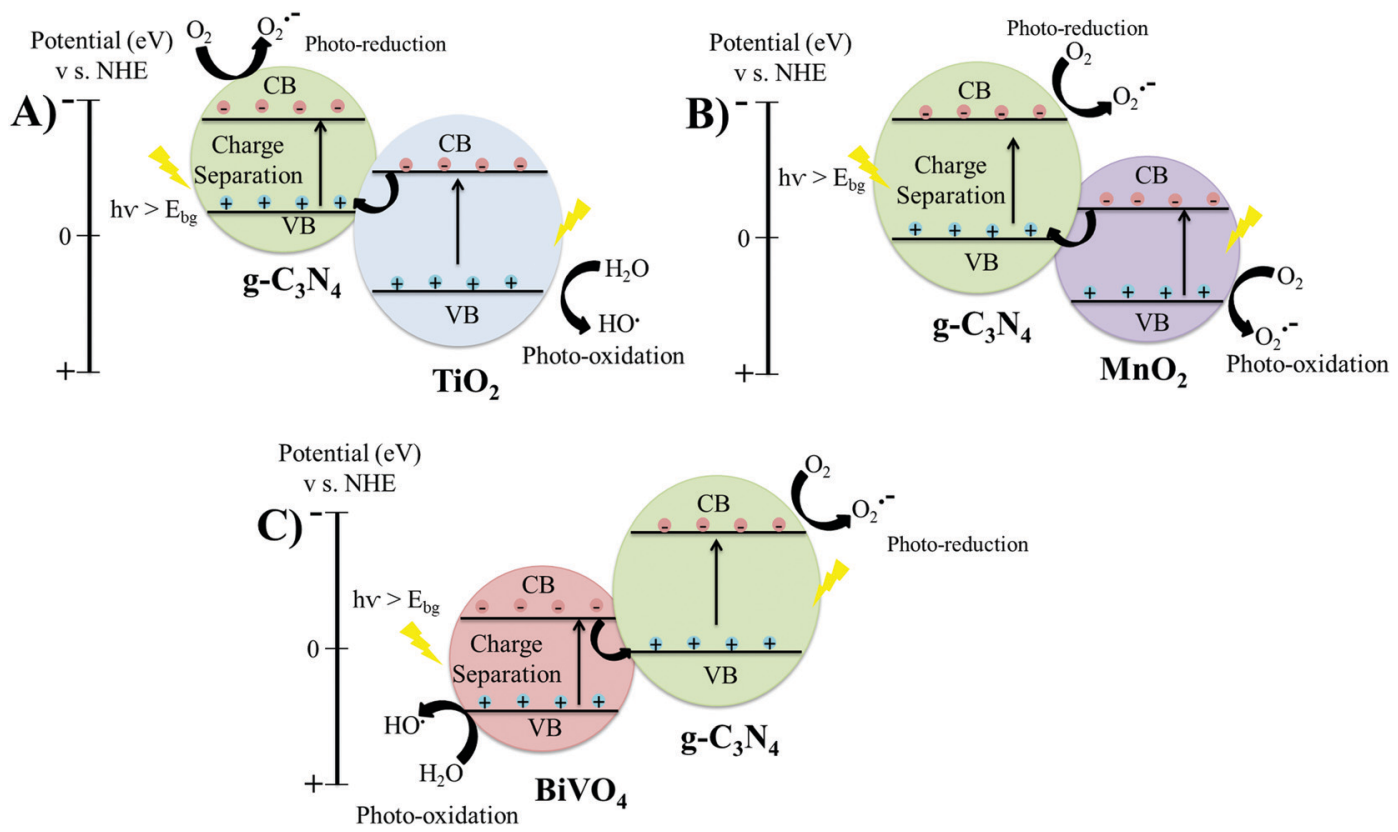

Fig. 6 Schematic of band structures and charge transfer mechanism in direct Z-scheme heterojunction structures: $(A) g-C_{3} N_{4}-T_{i O} ;(B) g-C_{3} N_{4} / M_{n} O_{2}$; and (C) $\mathrm{TBiVO}_{4} / \mathrm{g}-\mathrm{C}_{3} \mathrm{~N}_{4}$

undergo recombination reactions. Meanwhile, the photoinduced holes remain localised at the $\mathrm{VB}$ of $\mathrm{BiVO}_{4}$ to cause photo-reduction reaction and electrons on the $\mathrm{CB}$ of $\mathrm{g}-\mathrm{C}_{3} \mathrm{~N}_{4}$ to cause photo-oxidation reactions, as shown in Fig. 6(C). Rhodamine $\mathrm{B}$ was photo-catalytically degraded at a kinetic constant of $41 \times 10^{-3} \mathrm{~min}^{-1}$ using the $\mathrm{BiVO}_{4} / \mathrm{g}-\mathrm{C}_{3} \mathrm{~N}_{4}$ nanosheet. ${ }^{99}$

Density functional theory (DFT) calculations are also performed to estimate the physical factors such as relative energy band positions and structures of the heterojunction photocatalysts. ${ }^{100}$ For instance, the band gaps of $\mathrm{CN}$ and CdS in the $\mathrm{CN} / \mathrm{CdS}$ heterojunction were estimated from the density of states (DOS) calculation to be 2.27 and $2.36 \mathrm{eV}$, respectively. The CB and VB positions of CdS were found at -0.5 and $1.86 \mathrm{~V}$, which were higher than the $\mathrm{CB}$ and VB positions of $\mathrm{CN}$ at -1.15 and $1.61 \mathrm{~V} .^{101}$ The photo-generated electrons showed migration from CdS to $\mathrm{CN}$, while the holes transferred from $\mathrm{CN}$ to $\mathrm{CdS}$. The transfer of charge carriers led to the creation of an internal electric field, which further promotes interfacial charge transfer and inhibits the reverse motion of the charge carriers. Therefore, type II heterojunction structure was predicted for the $\mathrm{CN} / \mathrm{CdS}$ interface from the energy band position DFT calculations. ${ }^{101}$ The DOS calculations of another work on $\mathrm{CN} /$ $\mathrm{SnS}_{2}$ showed that the $\mathrm{CB}$ and $\mathrm{VB}$ positions of $\mathrm{CN}$ were higher than those of $\mathrm{SnS}_{2} \cdot{ }^{102}$ The internal electric field however supported the migration of week electrons from the $\mathrm{CB}$ of $\mathrm{SnS}_{2}$ to the VB of $\mathrm{CN}$, thereby exhibiting a typical direct Zscheme heterojunction structure. ${ }^{102}$

The heterojunction materials also showed the advantages of recyclability and reusability for catalytic application. ${ }^{103}$ The direct Z-scheme heterojunction structure of $\mathrm{CeO}_{2} / \mathrm{TiO}_{2}$ led to a total decrease of $1-2 \%$ in the catalytic efficiency after three continuous cycles. No deformation in the structure of the heterojunction material was observed in the XRD and XPS spectra, confirming the stability of the material. ${ }^{103}$ Similarly, another $\mathrm{CeO}_{2} / \mathrm{CdS}$ heterojunction material showed over 90.5\% degradation efficiency even after five cycles, which indicated good recyclability of the heterojunction material. ${ }^{104}$

\subsection{Concluding remarks and strategies for improving heterojunction materials}

The engineering of heterojunction structures is one of the most promising approaches towards achieving enhanced catalysis of model pollutant molecules such as methylene blue and rhodamine B, present in wastewater. Conventionally employed heterojunction structures for wastewater treatment are type II and direct Z-Scheme. Type-II heterojunctions support effective spatial charge separation and fast electron transfer mechanisms, leading to a higher catalytic performance than that of pristine semiconducting materials for the degradation of dyes with kinetic constant $k=5-20 \times 10^{-3} \min ^{-1}$. The redox ability of type-II heterojunction materials is somewhat compromised because the photo-reduction reactions occur on semiconducting materials with a lower reduction potential, and photooxidation reactions occur on semiconducting material with a lower oxidation potential. The direct Z-scheme heterojunctions offer efficient separation of charge carriers as well as redox ability as the charge transfer mechanism of Z-scheme heterojunctions is opposite to that of type-II heterojunction structures, therefore leading to enhanced catalysis of pollutant molecules with kinetic constant $k=30-70 \times 10^{-3} \mathrm{~min}^{-1}$.

Type II and direct Z-scheme heterojunctions have been widely explored over the past few years. After careful reviewing, research gaps and challenges associated with type II and direct Z-scheme heterojunctions have been identified. The charge 
transfer mechanism of type II heterojunctions is still debatable as it is difficult to achieve the desirable separation of charges in the described mechanism. The redox abilities of the semiconducting photocatalyst are also undermined, which overall attenuates the superior catalytic properties of the heterojunctions. Although, direct Z-scheme heterojunctions seem to overcome the drawbacks of type II heterojunctions still several approaches are required to enhance the photocatalytic performance such as alignment of the Fermi level of the semiconducting materials by doping or employing co-catalysts (Ag, $\mathrm{Au}$, $\mathrm{Pt}$ ). The incorporation of a suitable co-catalyst can enhance the charge separation as well as reduce the photocatalytic reaction barrier. Rational engineering of the morphology and interface regulation of the heterojunctions lead to enhanced photocatalytic efficiency. For instance, designing 2D/2D heterojunction nanosheets provides a larger area of contact enabling easy flux of electrons across the surface of the heterojunction structures to carry out the redox reactions. ${ }^{83}$

\section{Conclusions, challenges and prospects}

Schottky-like and heterojunction structures were discussed to link the charge transfer mechanisms associated with the unique combinatorial arrangement of materials to their catalytic performance. The changes in the physical and photoelectrochemical properties were correlated with the degradation of model pollutants as a route to further improve the general efficiency of relevant photo and electro catalytic processes. Both Schottky-like and heterojunction materials were found to exhibit higher catalytic performance than pristine semiconducting materials towards remediation of organic pollutants due to enhanced charge separation and suppressed recombination of charge carriers.

The Schottky-like materials show a non-linear relationship with respect to metal loading, which is interesting since this needs to be carefully optimized to achieve efficient properties and catalytic performance. A major challenge related to the fabrication of Schottky-like materials is the employment of noble metals such as $\mathrm{Au}, \mathrm{Ag}$, and Pt to couple with semiconducting materials, as they are present in scarce quantity in nature and also are very costly. The use of conductive non-noble metals or alloys such as stainless steel needs to be explored towards the next generation of more scalable Schottky-like materials.

The semiconductor heterojunction structures also provide an alternative due to their improved electrochemical properties and catalysis compared to those of pristine semiconducting materials without the need for noble metals. The most commonly employed semiconductor heterojunction structures are type-II and direct Z-scheme, which have similar band alignment, but the direction of flow of charge is opposite, and thus can easily be confused with each other. Therefore, the band structures and energy orbitals of the heterojunction materials through theoretical calculations, structural modelling or time-resolved characterization techniques must be explored to acquire the true picture of charge transport mechanisms and intermediate formation during the catalytic reactions. A deeper understanding of the charge separation and transport pathway at the interface will enable the design of new heterojunction structures with better catalytic efficiency. Future work should also be focussed on explaining the plausible charge carrier transfer mechanisms in heterojunction materials comprising more than two semiconducting materials.

Furthermore, the deposition and stabilization of nanolayered Schottky-like or heterojunction structures across conductive and porous substrate materials or membranes ${ }^{106}$ would mitigate technological issues such as recovery and re-use of catalysts or issues related to mass transfer limitations existing in dense catalytic materials. The Schottky-like or heterojunction membranes represent a highly novel class of separation materials, with improved available surface area and density of catalytically active sites compared to pristine semiconducting materials. Therefore, new strategies and materials for the preparation of Schottky-like and heterojunction structures across conductive membranes are required to enable primary filtration of wastewater with enhanced catalysis at surface and pore structures, high selectivity towards target pollutants, visible light activation, and high photo-stability of the materials.

\section{Conflicts of interest}

There are no conflicts to declare.

\section{References}

1 A. Mills and S. Le Hunte, J. Photochem. Photobiol., A, 1997, 108, 1-35.

2 H. Tong, S. Ouyang, Y. Bi, N. Umezawa, M. Oshikiri and J. Ye, Adv. Mater., 2012, 24, 229-251.

3 A. Merenda, A. Rana, A. Guirguis, D. M. Zhu, L. Kong and L. F. Dumée, J. Phys. Chem. C, 2019, 123, 2189-2201.

4 A. Guirguis, S. R. Polaki, G. Sahoo, S. Ghosh, M. Kamruddin, A. Merenda, X. Chen, J. W. Maina, G. Szekely and L. Dumee, Carbon, 2020, 168, 32-41.

5 R. T. Tung, Mater. Sci. Eng., R, 2001, 35, 1-138.

6 X. Ding, Y. Zhao, H. Xiao and L. Qiao, Appl. Phys. Lett., 2021, 118, 091601.

7 X. Feng, C. Huang, V. Lui, R. Khangura and Z. Lu, Appl. Phys. Lett., 2005, 86, 143511.

8 Y.-s. Fu, J. Li and J. Li, Nanomaterials, 2019, 9, 359.

9 R. Ghita, C. Logofatu, C. Negrila, A. Manea, M. Cernea and M. Lazarescu, J. Optoelectron. Adv. Mater., 2005, 7, 3033-3037.

10 H. Wang, L. Zhang, Z. Chen, J. Hu, S. Li, Z. Wang, J. Liu and X. Wang, Chem. Soc. Rev., 2014, 43, 5234-5244.

11 B. Sharma and R. Purohit, Semiconductor heterojunctions, Elsevier, 2015.

12 Q. Su, Y. Li, R. Hu, F. Song, S. Liu, C. Guo, S. Zhu, W. Liu and J. Pan, Adv. Sustainable Syst., 2020, 4, 2000130. 
13 H. Li, H. Hu, C. Bao, F. Guo, X. Zhang, X. Liu, J. Hua, J. Tan, A. Wang, H. Zhou, B. Yang, Y. Qu and X. Liu, Sci. Rep., 2016, 6, 29327.

14 X. Kong, L. Zhang, B. Liu, H. Gao, Y. Zhang, H. Yan and X. Song, RSC Adv., 2019, 9, 863-877.

15 M. Farhat, S. Kais and F. H. Alharbi, Sci. Rep., 2017, 7, 14253.

16 A. J. Wirth-Lima, P. P. Alves-Sousa and W. Bezerra-Fraga, SN Appl. Sci., 2020, 2, 246.

17 Y.-S. Fu, J. Li and J. Li, Nanomaterials, 2019, 9, 359.

18 M. R. Khan, T. W. Chuan, A. Yousuf, M. N. K. Chowdhury and C. K. Cheng, Catal. Sci. Technol., 2015, 5, 2522-2531.

19 J. Low, J. Yu, M. Jaroniec, S. Wageh and A. A. Al-Ghamdi, Adv. Mater., 2017, 29, 1601694.

20 F. Teng, K. Hu, W. Ouyang and X. Fang, Adv. Mater., 2018, 30, 1706262.

21 G. L. Chiarello, M. H. Aguirre and E. Selli, J. Catal., 2010, 273, 182-190.

22 C. Young, T. M. Lim, K. Chiang, J. Scott and R. Amal, Appl. Catal., B, 2008, 78, 1-10.

23 K. Gurunathan, Int. J. Hydrogen Energy, 2004, 29, 933-940.

24 Z. Yi, A. Merenda, L. Kong, A. Radenovic, M. Majumder and L. F. Dumée, Sci. Rep., 2018, 8, 8154.

25 J.-D. Xiao, L. Han, J. Luo, S.-H. Yu and H.-L. Jiang, Angew. Chem., Int. Ed., 2018, 57, 1103-1107.

26 S. Zhang, H. Lu, G. Rui, C. Lv, J. He, Y. Cui and B. Gu, Appl. Phys. B: Lasers Opt., 2020, 126, 135.

27 J. W. Maina, A. Merenda, M. Weber, J. M. Pringle, M. Bechelany, L. Hyde and L. F. Dumée, Crit. Rev. Solid State Mater. Sci., 2020, 1-22, DOI: 10.1080/ 10408436.2020.1819200.

28 J. A. Dionne and H. A. Atwater, MRS Bull., 2012, 37, 717-724.

29 S. C. Warren and E. Thimsen, Energy Environ. Sci., 2012, 5, 5133-5146.

30 S. Zeng, K.-T. Yong, I. Roy, X.-Q. Dinh, X. Yu and F. Luan, Plasmonics, 2011, 6, 491.

31 S. Seong, I.-S. Park, Y. C. Jung, T. Lee, S. Y. Kim, J. S. Park, J.-H. Ko and J. Ahn, Mater. Des., 2019, 177, 107831.

32 A. P. Manuel and K. Shankar, Nanomaterials, 2021, 11, 1249.

33 A. Zada, P. Muhammad, W. Ahmad, Z. Hussain, S. Ali, M. Khan, Q. Khan and M. Maqbool, Adv. Funct. Mater., 2020, 30, 1906744.

34 X. Zhu, J. Wang, D. Yang, J. Liu, L. He, M. Tang, W. Feng and X. Wu, RSC Adv., 2021, 11, 27257-27266.

35 A. Merenda, M. Weber, M. Bechelany, F.-M. Allioux, L. Hyde, L. Kong and L. F. Dumée, Appl. Surf. Sci., 2019, 483, 219-230.

36 J. Z. Y. Tan, Y. Fernández, D. Liu, M. Maroto-Valer, J. Bian and X. Zhang, Chem. Phys. Lett., 2012, 531, 149-154.

37 L. J. Brillson, Surf. Sci. Rep., 1982, 2, 123-326.

38 J. Yu, L. Qi and M. Jaroniec, J. Phys. Chem. C, 2010, 114, 13118-13125.

39 C.-H. Lin, J.-H. Chao, C.-H. Liu, J.-C. Chang and F.-C. Wang, Langmuir, 2008, 24, 9907-9915.
40 H. Shi, X. Wang, M. Zheng, X. Wu, Y. Chen, Z. Yang, G. Zhang and H. Duan, Adv. Mater. Interfaces, 2016, 3, 1600588.

41 P. K. Kalambate, Dhanjai, Z. Huang, Y. Li, Y. Shen, M. Xie, Y. Huang and A. K. Srivastava, TrAC, Trends Anal. Chem., 2019, 115, 147-161.

42 R. Nawaz, C. F. Kait, H. Y. Chia, M. H. Isa and L. W. Huei, Environ. Technol. Innovation, 2020, 19, 101007.

43 P. Kumari, N. Bahadur, L. A. O'Dell, L. Kong, A. Sadek, A. Merenda and L. F. Dumée, Sep. Purif. Technol., 2021, 258, 118011.

$44 \mathrm{~J} . \mathrm{Li}$ and H. C. Zeng, Angew. Chem., Int. Ed., 2005, 44, 4342-4345.

45 J. Ghilane, F.-R. F. Fan, A. J. Bard and N. Dunwoody, Nano Lett., 2007, 7, 1406-1412.

46 Y. F. Zhu, D. H. Fan and W. Z. Shen, J. Phys. Chem. C, 2008, 112, 10402-10406.

47 H. Liu, X. Dong, X. Wang, C. Sun, J. Li and Z. Zhu, Chem. Eng. J., 2013, 230, 279-285.

48 S. Son, J. M. Lee, S.-J. Kim, H. Kim, X. Jin, K. K. Wang, M. Kim, J. W. Hwang, W. Choi, Y.-R. Kim, H. Kim and S.-J. Hwang, Appl. Catal., B, 2019, 257, 117875.

49 Z. Sun, T. Liao, Y. Dou, S. M. Hwang, M.-S. Park, L. Jiang, J. H. Kim and S. X. Dou, Nat. Commun., 2014, 5, 3813.

50 J. A. Singh, N. F. W. Thissen, W.-H. Kim, H. Johnson, W. M. M. Kessels, A. A. Bol, S. F. Bent and A. J. M. Mackus, Chem. Mater., 2018, 30, 663-670.

51 B. C. Mallick, C.-T. Hsieh, K.-M. Yin, Y. A. Gandomi and K.-T. Huang, ECS J. Solid State Sci. Technol., 2019, 8, N55-N78.

52 P. Zhou, J. Yu and M. Jaroniec, Adv. Mater., 2014, 26, 4920-4935.

53 H. Tada, T. Mitsui, T. Kiyonaga, T. Akita and K. Tanaka, Nat. Mater., 2006, 5, 782-786.

54 C. Ren, B. Yang, M. Wu, J. Xu, Z. Fu, Y. lv, T. Guo, Y. Zhao and C. Zhu, J. Hazard. Mater., 2010, 182, 123-129.

55 C. Dahmen, A. N. Sprafke, H. Dieker, M. Wuttig and G. V. Plessen, Appl. Phys. Lett., 2006, 88, 011923.

56 Z. Jiang, W. Wei, D. Mao, C. Chen, Y. Shi, X. Lv and J. Xie, Nanoscale, 2015, 7, 784-797.

57 O. Bechambi, M. Chalbi, W. Najjar and S. Sayadi, Appl. Surf. Sci., 2015, 347, 414-420.

58 X. Zhu, X. Liang, P. Wang, Y. Dai and B. Huang, Appl. Surf. Sci., 2018, 456, 493-500.

59 S. T. Kochuveedu, D.-P. Kim and D. H. Kim, J. Phys. Chem. C, 2012, 116, 2500-2506.

60 S. Cao, F. Tao, Y. Tang, Y. Li and J. Yu, Chem. Soc. Rev., 2016, 45, 4747-4765.

61 J. Adekoya, O. Olurotimi, T. Siyanbola, E. Dare and N. Revaprasadu, Band structure, Morphology, Functionality, and size dependent properties of metal nanoparticles, Nobel and precious metals properties, nanoscale effects and applications, IntechOpen, 2018, pp. 15-41.

62 T.-T. Yang, W.-T. Chen, Y.-J. Hsu, K.-H. Wei, T.-Y. Lin and T.-W. Lin, J. Phys. Chem. C, 2010, 114, 11414-11420.

63 H. Wang, W. Zhao, C.-H. Xu, H.-Y. Chen and J.-J. Xu, Chem. Sci., 2019, 10, 9308-9314. 
64 S. T. Kochuveedu, Y. H. Jang and D. H. Kim, Chem. Soc. Rev., 2013, 42, 8467-8493.

65 V. L. Chandraboss, Mater. Today: Proc., 2021, 36, 907-913.

66 R. Rahimi, M. Heidari-Golafzani and M. Rabbani, Superlattices Microstruct., 2015, 85, 497-503.

67 F. Dong, Z. Zhao, Y. Sun, Y. Zhang, S. Yan and Z. Wu, Environ. Sci. Technol., 2015, 49, 12432-12440.

68 Y. Gao, Y. Huang, Y. Li, Q. Zhang, J.-J. Cao, W. Ho and S. C. Lee, ACS Sustainable Chem. Eng., 2016, 4, 6912-6920.

69 Y. Zhang, C. Yuan, Q. Wang, M. R. Hoffmann, X. Zhang, J. Nie, C. Hu, S. Chen, J. Qiao, Q. Wang and Y. Cong, Electrochim. Acta, 2019, 328, 135124.

70 C. Yao, J. Lin, L. Li, Y. Qu, K. Jiang, Z. Hu, N. Xu, J. Sun and J. Wu, J. Phys. Chem. C, 2020, 124, 10941-10950.

71 X. He, T. Kai and P. Ding, Environ. Chem. Lett., 2021, 19, 4563-4601.

72 L. Wei, C. Yu, Q. Zhang, H. Liu and Y. Wang, J. Mater. Chem. A, 2018, 6, 22411-22436.

73 S. Perlman and D. Feucht, Solid-State Electron., 1964, 7, 911-923.

74 T. Trindade, P. O'Brien and N. L. Pickett, Chem. Mater., 2001, 13, 3843-3858.

75 B. Yacobi, Semiconductor Materials: An Introduction to Basic Principles, 2003, pp. 135-170.

76 F. Mei, K. Dai, J. Zhang, W. Li and C. Liang, Appl. Surf. Sci., 2019, 488, 151-160.

77 J. Wang, Q. Zhang, F. Deng, X. Luo and D. D. Dionysiou, Chem. Eng. J., 2020, 379, 122264.

78 X. Jia, Q. Han, M. Zheng and H. Bi, Appl. Surf. Sci., 2019, 489, 409-419.

79 Q. Xu, L. Zhang, J. Yu, S. Wageh, A. A. Al-Ghamdi and M. Jaroniec, Mater. Today, 2018, 21, 1042-1063.

80 Q. Xu, L. Zhang, B. Cheng, J. Fan and J. Yu, Chem, 2020, 6, 1543-1559.

81 X. Li, J. Liu, J. Huang, C. He, Z. Feng, Z. Chen, L. Wan and F. Deng, Acta Phys.-Chim. Sin., 2020, 37, 2010030.

82 T. Di, Q. Xu, W. Ho, H. Tang, Q. Xiang and J. Yu, ChemCatChem, 2019, 11, 1394-1411.

83 F. He, A. Meng, B. Cheng, W. Ho and J. Yu, Chin. J. Catal., 2020, 41, 9-20.

84 J. Mu, F. Teng, H. Miao, Y. Wang and X. Hu, Appl. Surf. Sci., 2020, 501, 143974.

85 R. Wang, J. Shen, W. Zhang, Q. Liu, M. Zhang, Zulfiqar and H. Tang, Ceram. Int., 2020, 46, 23-30.
86 J. Low, C. Jiang, B. Cheng, S. Wageh, A. A. Al-Ghamdi and J. Yu, Small Methods, 2017, 1, 1700080.

87 J. Su, G.-D. Li, X.-H. Li and J.-S. Chen, Adv. Sci., 2019, 6, 1801702.

88 J. Jia, W. Sun, Q. Zhang, X. Zhang, X. Hu, E. Liu and J. Fan, Appl. Catal., B, 2020, 261, 118249.

89 N. Wetchakun, S. Chaiwichain, B. Inceesungvorn, K. Pingmuang, S. Phanichphant, A. I. Minett and J. Chen, ACS Appl. Mater. Interfaces, 2012, 4, 3718-3723.

90 M. Zhou, J. Yu, S. Liu, P. Zhai and L. Jiang, J. Hazard. Mater., 2008, 154, 1141-1148.

91 A. Ghobadi, T. G. Ulusoy, R. Garifullin, M. O. Guler and A. K. Okyay, Sci. Rep., 2016, 6, 30587.

92 S. Li, C. Wang, M. Cai, F. Yang, Y. Liu, J. Chen, P. Zhang, X. Li and X. Chen, Chem. Eng. J., 2022, 428, 131158.

93 H. M. Mousa, J. F. Alenezi, I. M. A. Mohamed, A. S. Yasin, A.-F. M. Hashem and A. Abdal-hay, J. Alloys Compd., 2021, 886, 161169.

94 C. Belver, M. Hinojosa, J. Bedia, M. Tobajas, M. A. Alvarez, V. Rodríguez-González and J. J. Rodriguez, Materials, 2017, 10, 960 .

95 H. Ma, B. Hao, W. Song, J. Guo, M. Li and L. Zhang, Materials, 2021, 14, 3299.

96 J. Yu, S. Wang, J. Low and W. Xiao, Phys. Chem. Chem. Phys., 2013, 15, 16883-16890.

97 W. Gu, F. Lu, C. Wang, S. Kuga, L. Wu, Y. Huang and M. Wu, ACS Appl. Mater. Interfaces, 2017, 9, 28674-28684.

98 P. Xia, B. Zhu, B. Cheng, J. Yu and J. Xu, ACS Sustainable Chem. Eng., 2018, 6, 965-973.

99 Z. Sun, Z. Yu, Y. Liu, C. Shi, M. Zhu and A. Wang, J. Colloid Interface Sci., 2019, 533, 251-258.

100 J. Xue and J. Bao, Surf. Interfaces, 2021, 25, 101265.

101 J. Liu, J. Phys. Chem. C, 2015, 119, 28417-28423.

102 J. Liu and E. Hua, J. Phys. Chem. C, 2017, 121, 25827-25835.

103 H. Yan, R. Wang, R. Liu, T. Xu, J. Sun, L. Liu and J. Wang, Appl. Catal., B, 2021, 291, 120096.

104 R. Zou, L. Li, L. Yang, J. Lan, H. Liu, B. Dou, J. Shang and S. Lin, Cellulose, 2021, 28, 11081-11096.

105 J. Yu, W. Wang and B. Cheng, Chem. - Asian J., 2010, 5, 2499-2506.

106 P. Kumari, N. Bahadur, M. Cretin, L. Kong, L. A. O’Dell, A. Merenda and L. F. Dumée, React. Chem. Eng., 2021, 6, 1508-1526. 